\title{
The Dynamics of School Attainment of England's Ethnic Minorities
}

\author{
Deborah Wilson, Simon Burgess and Adam Briggs
}

\section{Contents}

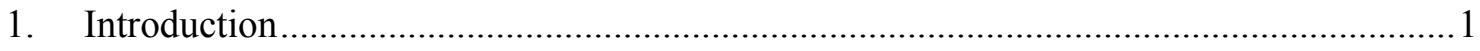

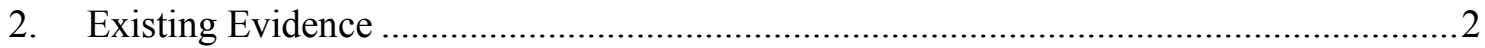

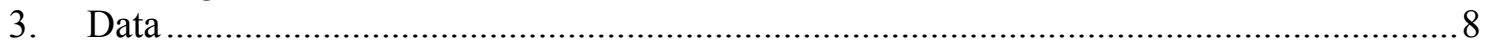

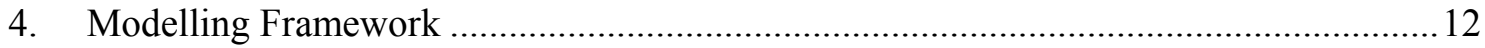

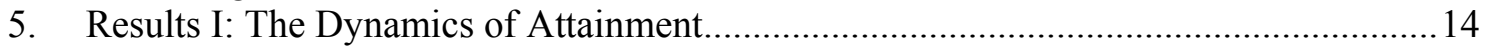

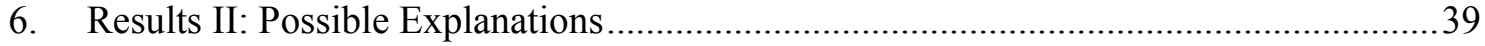

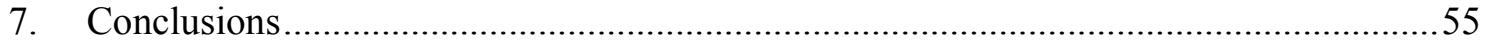

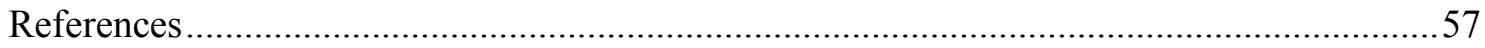

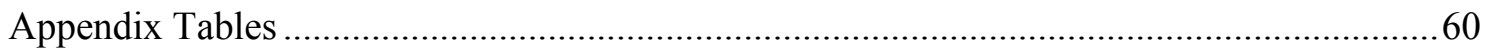

CASEpaper 105

January 2006
Centre for Analysis of Social Exclusion

London School of Economics

Houghton Street

London WC2A $2 \mathrm{AE}$

CASE enquiries - tel: 02079556679 


\section{Centre for Analysis of Social Exclusion}

The ESRC Research Centre for Analysis of Social Exclusion (CASE) was established in October 1997 with funding from the Economic and Social Research Council. It is located within the Suntory and Toyota International Centres for Economics and Related Disciplines (STICERD) at the London School of Economics and Political Science, and benefits from support from STICERD. It is directed by Howard Glennerster, John Hills, Kathleen Kiernan, Julian Le Grand, Anne Power and Carol Propper.

Our Discussion Paper series is available free of charge. We also produce summaries of our research in CASEbriefs, and reports from various conferences and activities in CASEreports. To subscribe to the CASEpaper series, or for further information on the work of the Centre and our seminar series, please contact the Centre Manager, Jane Dickson, on:

Telephone: $\quad$ UK+20 79556679

Fax: $\quad$ UK+20 $\quad$ I9556951

Email: $\quad$ j.dickson@1se.ac.uk

Web site: http://sticerd.lse.ac.uk/case

(C) Deborah Wilson

Simon Burgess

Adam Briggs

All rights reserved. Short sections of text, not to exceed two paragraphs, may be quoted without explicit permission provided that full credit, including (C) notice, is given to the source. 


\title{
Editorial Note and Acknowledgements
}

Deborah Wilson is a Senior Research Officer at the Centre for Market and Public Organisation (CMPO) at the University of Bristol. Simon Burgess is Professor of Economics in the Department of Economics, University of Bristol, and Director of the CMPO. Adam Briggs is a Research Assistant at the CMPO.

Thanks to the Leverhulme Trust for funding this research through CMPO. Thanks also for comments to Howard Glennerster, Paul Gregg, Ron Johnston, Carol Propper and Leon Tikly. None of the above is responsible for any mistakes in the paper, or the views expressed.

Corresponding author: simon.burgess@bristol.ac.uk

\begin{abstract}
We exploit a universe dataset of state school students in England with linked test score records to document the evolution of attainment through school for different ethnic groups. The analysis yields a number of striking findings. First, we show that, controlling for personal characteristics, all minority groups make greater progress than white students over secondary schooling. Second, much of this improvement occurs in the high-stakes exams at the end of compulsory schooling. Third, we show that for most ethnic groups, this gain is pervasive, happening in almost all schools in which these students are found. We address some of the usual factors invoked to explain attainment gaps: poverty, language, school quality, and teacher influence. We conclude that our findings are more consistent with the importance of factors like aspirations and attitudes.
\end{abstract}

Keywords: Ethnic test score gap, school attainment, education JEL Numbers: I20, J15 


\section{Introduction}

The accumulation of human capital remains one of the key factors in the economic success of an individual and a community. It has a major impact on earnings and, more broadly, on social standing. Formal schooling is the context for much of this, and so has been an important focus for studies investigating the roots of racial and ethnic disadvantage. Jencks and Phillips (1998, p. 4), referring to the US experience, put it as follows: "Reducing the test score gap is probably both necessary and sufficient for substantially reducing racial inequality in educational attainment and earnings". There is a large literature in the US on ethnic differences in test scores and skills, recently surveyed by Neal (2005). Often these studies are snapshots of a sample of students, but one recent contribution by Fryer and Levitt (2005) follows a cohort of children through the early years of schooling. There is less evidence for the UK, which we discuss below.

In this paper, we exploit a universe dataset of school students in England, following two cohorts of pupils, respectively through secondary schooling (from age 11 to the end of compulsory schooling at 16) and most of primary schooling (from age 7 to 11). Using linked test score records, we document the evolution of attainment for different ethnic groups through school.

The analysis confirms some facts on ethnic attainment gaps and yields a number of striking findings. We confirm that in the high stakes exams taken at age 16, pupils from some ethnic groups achieve considerably lower scores than white pupils on average: pupils with Black Caribbean heritage, other Black heritage or Pakistani ethnicity. Students with Indian or Chinese ethnicity score much higher than their white peers. We focus on three main new findings. First, we show that, controlling for a small set of personal characteristics, all ethnic minority groups make greater progress on average than white students between ages 11 and 16. For some groups, this relative progress is substantial. During the period of secondary schooling, pupils from all groups are either catching up with white pupils (Black Caribbean or other Black heritage), or overtaking white pupils (Indian, Pakistani, Bangladeshi ethnicities or Black African heritage). The counterpart of this finding is that the group with the most problematic path through secondary schooling is disadvantaged white boys. Second, we show that much of this improvement occurs in the high-stakes exams at the end of compulsory schooling. These exams govern entry into further education and are important for school-leavers jobs. One interpretation of this is that students and families with greater aspirations will place more weight on these exams. An alternative interpretation - different marking practices for different exams - is 
not supported. ${ }^{1}$ Third, we show that for most ethnic groups, this gain relative to white students is pervasive, happening in almost all schools in which these students are found. This suggests that, for these groups at least, teaching practices relevant to differential ethnic attainment cannot be of first order importance. This near-universality of gain is not true for pupils of Black Caribbean or other Black heritage, with about half schools showing a relative improvement in scores for these pupils.

Our analysis addresses some of the usual factors invoked to explain attainment gaps. These are typically about levels rather than growth in attainment, and are furthermore set up to explain poorer performance by minorities, which is not universally what we find here. We consider the roles of poverty, language, school quality, and teacher influence, and we analyse attainment gaps at the lower end of the distribution as well as the average.

We structure the paper as follows. In the next section we review the relevant literature for the US and the UK. Section 3 details the dataset, the nature of our sample and the tests taken by schoolchildren in England. Section 4 presents the results and Section 5 explores some possible explanations of the findings. Section 6 concludes.

\section{Existing Evidence}

Here we review the evidence on the relative achievement of different ethnic groups, in the US and the UK. We first describe the facts, the gaps that have been reported at different stages of schooling, before looking at the various explanations for those gaps.

\section{Evidence}

Public concern about education in the UK arose with the influx of new immigrants in the 1960s, both from the host population, and from Caribbean parents worried that state schools were failing their children. A Government Select Committee produced a report in 1974 on "Education disadvantage and the educational needs of immigrants" (HMSO, 1974), and in 1985 a major report from the Swann Committee investigated the educational performance of students from different ethnic groups and made recommendations on multicultural education (HMSO, 1985). The evidence on differences in attainment shows diverse outcomes for different groups in the UK: see

1 We use data from the written test components of the exams, and at ages 11, 14 and 16 these are all marked in the same way: remote from the school and not by the pupils' own teachers. 
Modood's (2005) summary of the evidence on differences in adults' qualifications. Focussing more on schools, a recent report from the Department for Education and Skills (DfES 2005) documents the relative achievement of ethnic groups in England in the 2003/04 academic year across the four Key Stages of the National Curriculum; tests taken at the ages of 7, 11, 14 and 16 (KS1 to 4 respectively) by all pupils in state maintained schools. ${ }^{2}$ Students of Chinese and Indian ethnic origin show high levels of achievement relative to the national average, while Black Caribbean, Pakistani and Bangladeshi students relatively underachieve. The report also looks at measures of value added; at the progress of the same children across successive Key Stages. Bangladeshis and Black Africans improve relative to the national average between KS1 and 2, and also between KS3 and 4. Pakistani students relatively improve between KS3 and 4, while Indian, Chinese and students from Other minority ethnic backgrounds show relative improvement between each Key Stage. Conversely, the achievement of white, Black Caribbean and Other Black students all decline relatively to the national average.

Bradley and Taylor (2004) use pooled cross sectional data between 1992 and 1998 for England and Wales to investigate the determinants of educational attainment at the age of 16 across different ethnic groups. Their data allows them to consider the following ethnic categorisations: white, Afro-Caribbeans, Bangladeshi/Pakistani, Indian, Other. Looking first at the raw data, they observe the following order of relative performance (highest performance first): Other, Indian, white, Bangladeshi/Pakistani, Afro-Caribbean. While there is a general improvement in performance between 1992-1998, the ranking remains unchanged. Once they control for a range of individual, school and labour market covariates, they find that all non-white ethnic groups perform better in the exams at age 16 except Afro-Caribbeans. It is in maths that the underperformance of this group is particularly pronounced.

Gillborn and Mirza (2000) confirm a complex picture of inequality regarding the relative performance of ethnic groups in UK schools. They look at local education authority (LEA) level data for students taking KS4 exams in 1998 and find that for each ethnic group there is at least one LEA where that group is highest achieving. Modood (2003) looks at data from the 4th National Survey of Ethnic Minorities (conducted by the Policy Studies Institute) and confirms that some minority ethnic groups underperform relative to white students while others perform better: Caribbean, Pakistani and Bangladeshi make up the former; Indian, African-Asian, Chinese and African the latter. In general, South Asian students relatively underachieve in the early years of schooling, but then See also Bhattacharya et al (2003) for a similar analysis carried out on earlier data. 
catch up and/or overtake their white peers. Modood also finds that minority ethnic students are more likely to stay on at school compared to white students and are as a result over-represented in post-compulsory education.

Turning to the US, there has been a focus on the underachievement of black students relative to their white peers since the Coleman Report of 1966, which attributed the black-white test score gap primarily to family background (Chubb and Loveless 2002). While more recent work has also looked at the relative performance of Hispanic and Asian students, it is the academic profile of African Americans that continues to be the main concern (Thernstrom 2002).

Neal (2005) provides a summary of the evidence on test score and skills gaps. He uses National Assessment of Educational Progress (NAEP) test score data, which provides annual data in reading and maths test scores for students aged 9 and 13 between 1971 and 1999. This shows that the black-white test score gap is always greater than 0.5 standard deviations (SDs), with some of the earlier gaps exceeding one SD. Neal also uses NLSY79 and NLSY97 data to compare the performance of 15-17 year olds' maths scores. While there is again some improvement across cohorts, in 1997 approximately 80\% of black males and females scored below the corresponding whites.

Cook and Evans (2000) also use NAEP data, from 1970-1988, to investigate the black-white test score gap for maths and reading at the ages of 9, 13 and 17 . They find that the gap decreases across the cohorts and that this is due to black students' performance improving; that of white students remains fairly static across the time period.

Phillips (2000) uses longitudinal data to examine whether the test score gap widens among children who start school with the same skills. She finds that African American students fall behind between the first and the ninth grade, especially in reading comprehension. She estimates that at least half the gap that exists at the end of twelfth grade can be attributed to the gap that existed at the beginning of the first grade.

Three recent US studies have focused on achievement gaps in the early years of schooling. Bali and Alvarez (2004) use data from the Pasadena Unified School District (PUSD) in California in which over $80 \%$ of the population is black or Hispanic. They examine when and how the black-white and Hispanic-white test score gaps develop in the first through fourth grades. They find that, while gaps develop for both blacks and Hispanics, the Hispanic-white gaps both develop later and are smaller than the black-white gaps, particularly in maths. In general, the gaps remain after the authors control for both school and individual factors. 
Fryer and Levitt (2004; 2005) use the Early Childhood Longitudinal Study kindergarten cohort (ECLS-K), a dataset following 20,000 children who entered kindergarten in the autumn of 1998. Fryer and Levitt (2004) observe the children through the autumn and spring of Kindergarten and the spring of first grade; their 2005 paper extends the panel over a further two years of schooling to the spring of third grade. Once they control for a small number of covariates, the black-white test score gap on entry to kindergarten is eliminated. Over the first two years of school, however, the achievement of black children falls behind their white, Hispanic and Asian peers. Fryer and Levitt (2005) show that black children continue to lose ground through second and third grades: on average by 0.1 SDs per year relative to whites over the first four years of schooling. By contrast, Hispanics and Asians gain.

So a complex picture emerges, both across different ethnic groups and at different stages of compulsory schooling. Much of the evidence, particularly for the UK, is based on repeated cross sections across time. In this paper, we add to this by following two cohorts of students and considering their relative progress across different Key Stages. As Phillips (2000) points out, the way the achievement gap changes as children age can shed light on its causes.

\section{Explanations}

\section{(A) NON-SCHOOL FACTORS}

While there is no evidence that genetic factors such as systematic differences in innate ability play a significant role in ethnic test score gaps (Nisbett 1998), the importance of other non-school factors such as family background in the relative achievement levels of different ethnic groups has been widely recognised since the 1966 Coleman Report. There is conflicting evidence, however, both on the extent to which such factors are important, and, more specifically, what precise factors may contribute to the systematic underachievement of certain minority ethnic groups. General societal attitudes to ethnic minorities may also play an important role.

Cook and Evans (2000), for example, investigate reasons for the convergence in NAEP test scores they observe between 1970 and 1988 using an Oaxaca decomposition. They calculate that changes in parental education account for one quarter of the observed convergence, while changes in the returns to parental education only account for two per cent. Brooks-Gunn et al (1996) concentrate on the role played by family and neighbourhood factors in the observed differences in test scores of black and white five year olds and conclude that both poverty and home environment factors are the big influences. Phillips et al (1998) investigate the impact of various aspects of family background on the underachievement of black five and six year olds relative to their white peers on the Peabody Picture Vocabulary Test (PPVT) and conclude 
that measures of the mother's socioeconomic status when growing up and measures of current parenting practices have more explanatory power than traditional measures of educational and economic inequality such as parental schooling and income.

For England and Wales, Bradley and Taylor investigate the differential impact across ethnic groups of a range of non-school based covariates on performance at age 16. They find that the exam performance of non-white students is more likely to be adversely affected by living in a single parent family, while both living in rented housing and the occupational status of the student's mother has a smaller impact on non-white relative to white students' performance.

Modood (2003) discusses the extent to which social class is a factor in the relative attainment of different ethnic groups. He argues that the role class plays should be qualified by the gender norms and expectations in different communities. Bhattacharya et al (2003) concur with this view. Modood further argues that the ambition among South Asians to be university educated is not constrained by class, but can be seen as integral to their social mobility ambitions. The issue of differential aspiration and its impact on attainment is also raised by Bradley and Taylor (2004) (and references cited therein) who find that whites are least likely to proceed to further education.

Finally, more broad social or cultural issues may act to depress minority ethnic achievement levels. Cook and Ludwig (1998) discuss the fear of "acting white" which may lead to academically successful black students being disparaged and/or reducing their effort in order to avoid taunts. Modood (2003) notes that this is one common explanation for the under achievement of Caribbean male students in the UK.

\section{(B) SYSTEMIC SCHOOLING FACTORS}

One potential explanation for achievement gaps that has been explored in the literature is that education policy or practice that is imposed on all students within the system may have a differential impact on particular ethnic groups. Jencks (1998), for example, discusses the different ways in which cognitive tests may be racially biased. In the UK, all students follow the National Curriculum and take the same tests at the end of four Key Stages. Racial bias in either the setting of the tests or the content of the curriculum on which they are based could have a differential impact on the achievement of minority ethnic students (Tikly 2005; Tomlinson 2001). State or nationwide accountability systems may also have unintended side effects that impact on student attainment. Clotfelter et al (2004), for example, show how the North Carolina accountability system made it more difficult for low-performing schools to retain teachers. 
(C) BETWEEN SCHOOL FACTORS: DIFFERENTIAL QUALITY OF SCHOOLS ATTENDED One reason why minority ethnic students may underachieve is that they attend schools of a worse quality. The evidence on this is mixed. Furthermore, as Neal (2005) points out, it may be racial differences per se and/or black-white differences in how families and children interact with schools that cause differences in attainment or progress as children move through school. Cook and Evans (2000) for example find that, between 1970 and 1988, schools attended by black students worsened in quality relative to those attended by whites, but that this coincided with a period of relative progress for black students. For young children, Fryer and Levitt (2004) find suggestive evidence that school quality plays a role. In their extended study (Fryer and Levitt 2005), however, school quality is less important in explaining test score differentials. Bali and Alvarez (2004) conclude that in Pasadena elementary education, such differentials are not explained by differences in the quality of schools attended. Bradley and Taylor (2004) note that school quality may in fact be endogenous in a model of educational attainment, if parents with greater resources choose to send their children to a school with a good exam performance.

(D) WITHIN SCHOOL FACTORS: SCHOOL PRACTICE; INSTITUTIONAL ISSUES

Finally, the potential impact of different aspects of school practice on differential attainment has been a focus in this literature. Clotfelter et al (2004) summarise the findings of five of their studies on the extent to which variation in teacher characteristics contributes to minority achievement gaps. All these studies use a rich North Carolina dataset which includes all students and all teachers. The authors conclude that, put together, the findings of these studies implicate the unequal distribution of teachers (as defined by their characteristics) as one of the many contributory factors to minority achievement gaps. In particular they highlight the uneven distribution of novice teachers both across schools and across classrooms within schools. Ehrenberg et al (1995) analyse how a teacher's race, gender and ethnicity (RGE) influences students both from the same RGE group as well as from other RGE groups, in terms of objective (test score) performance and subjective evaluation. They find that teacher RGE doesn't affect the former, but does have an impact on the latter. Ferguson (1998a) reviews the evidence on teacher expectations and concludes that teachers do have lower expectations for blacks than for whites and that this impacts on performance. These expectations are based on black students' previously worse past performance and behaviour and as a consequence racial disparities in achievement are perpetuated. Modood (2003) also highlights confrontational relationships with teachers as being part explanation for the underachievement of Caribbean male students in the UK, as well as discipline problems and high exclusion rates, plus racial bias in setting (ability grouping) practice. He states that no one explanation is entirely convincing, but some or all of these issues may account for part of the achievement gap. 
Overall, Jencks and Phillips (1998, page 42) conclude that traditional explanations for the black-white test score gap don't work very well. They suggest that large scale experiments should be conducted in the US "aimed at reducing uncertainty about the effects of schools' racial mix, class size, teacher selection systems, ability grouping, and many other policies". Jencks and Phillips" "best guess" is that successful new theories about the causes of the gap will focus more on differential interaction with and response to, for example, classroom experiences, rather than on differences in experience per se, as well as on psychological and cultural differences.

\section{Data}

In the following analysis, we use the Pupil Level Annual School Census (PLASC) dataset from the Department for Education and Skills (DfES). PLASC covers all pupils in primary and secondary schools in England and can be linked to each pupil's test score history. In addition, PLASC contains a number of personal and school characteristics: ethnicity, gender, within-year age, mother tongue, an indicator of family poverty (eligibility for Free School Meals, FSM, which is dependent on receipt of some welfare benefits), an indicator of Special Educational Needs (SEN, which measures learning or behavioural difficulties), and each pupil's postcode which locates them to around $100 \mathrm{~m} 2$. Of course, welfare receipt and so FSM status is a crude, dichotomous measure of poverty, and we should be cautious about comparing pupils with FSM across different ethnic groups: mean income level and family environment is likely to be different among FSM groups across ethnic groups. Some of the pupil characteristics are non time-varying: gender, ethnicity, within-year age and mother tongue. The time-varying ones are FSM and SEN status, location and school attended. In fact, these are only measured once, at the end point of each cohort, 2002. We discuss the implications of this for the results below.

We use test score data from the Key-stage tests that students now take throughout schooling. These are nationally set tests, with the final ones at age 16 being very important for subsequent progress in education or jobs. We follow two cohorts, one aged 11 in 2002 and one aged 16 in 2002; there is not yet available a single cohort covering progress through all the tests. The first cohort (C1) covers most of primary school, and we use results from Key-stage 1 tests (KS1, taken at age 7) taken in 1998 and Key-stage 2 tests (KS2, taken at age 11) in 2002. The second cohort (C2) covers all of compulsory secondary schooling, from age 11 to age 16 . We start the analysis with the scores that the students enter secondary schooling with, that is, their KS2 tests in 1997 . We then track progress through the Key-stage 3 tests (KS3, taken at age 14) taken in 2000 to the terminal Key-stage 4 tests (KS4, taken at age 16) in 2002. These 
final tests are also known as GCSE (General Certificate of Secondary Education), and we generally use that term below. At Key-stages 2 and 3, all students take assessments in English, Maths and Science. At GCSE, students can take a range of subjects but these three core subjects are mandatory for all. Key-stage 1 comprises both teacher assessment and tests, and covers reading, writing and maths. Thus subject selection does not arise as an issue, apart from GCSE, and to take account of that we provide results focusing on English, Maths and Science all the way through school.

We can distinguish the following ethnic groups: Black African Heritage; Black Caribbean Heritage; Black Other Heritage; Bangladeshi ethnicity; Indian ethnicity; Pakistani ethnicity; Chinese ethnicity; Other ethnicities; and White. ${ }^{3}$

\section{Analysis Sample}

We only focus on state school pupils in England, accounting for around 93\% of all pupils. This is because not all private schools carry out all the Key-stage tests and it is safest to cut all private schools out of the data. Exploiting the data as cohorts allows us to focus on pupil progress. We study the cohorts as balanced panels - that is, to only follow pupils for whom we have full test score records. In general, there are advantages and disadvantages of this, but in this case, the advantages are strong. The proportion of students who do have a full record is high, and the ability to track the same group through school without worrying about changing sample composition offers some very useful insights. Table 1 shows the sample sizes for our two cohorts, and provides a breakdown by ethnic group. In total we have 562,741 pupils in cohort 1 and 467,463 pupils in cohort 2. White pupils make up the vast majority of both samples $(89.19 \%$ in cohort 1 and $89.12 \%$ in cohort 2). Of the minority groups, the South Asian ethnicity pupils form the largest groups, about twice as numerous as the Black heritage groups.

We tackle the extent to which the analysis sample is unrepresentative of all students taking a particular test in the Appendix. With the exception of one group, students of Black African Heritage, the analysis cohort accounts for most

These are the 'old' ethnic categorisation tables used in PLASC. We are unable to use the finer 'new' ethnic categorisation tables, as it was optional which classification schools used in 2001/2002 and the majority chose the old categories. Clearly, some of these groups are quite heterogeneous. For example, Bhattacharyya et al 2003 note that the compulsory introduction of new ethnicity codes in 2003 (which included 'Mixed' categories such as White and Black Caribbean or White and Asian) resulted in fewer pupils being classified in the 'Other' group. Some further information from DfES (2005) shows that Black African pupils are principally from Nigeria, Somalia and Ghana. The catch-all Other ethnicity category includes principally students with Vietnamese, Arab and Latin American ethnicity, and pupils with mixed heritage. 
of the students sitting the test. Appendix Table 1 shows that, for example in the GCSE tests, the analysis sample accounts for $85 \%$ of Black Caribbean students, $81 \%$ of ethnic Bangladeshi students, $89 \%$ of Indian and $86 \%$ of Pakistani ethnic origin students. The average is $92 \%$ and the minimum is $77 \%$, apart from Black African heritage students. This group is rather different, with $97 \%$ of KS2 students covered, but only $69 \%$ of KS3 students and 59\% at GCSE. We return to this below.

Table 1: Sample sizes in cohorts 1 and 2 by ethnic group ${ }^{1}$

\begin{tabular}{lll}
\hline \hline Ethnic Group & Cohort 1 & Cohort 2 \\
\hline \multirow{2}{*}{ Black African } & 5,703 & 3,872 \\
Black Caribbean & $(1.01 \%)$ & $(0.83 \%)$ \\
& 7,815 & 6,351 \\
Black Other & $(1.39 \%)$ & $(1.36 \%)$ \\
& 4,382 & 3,597 \\
Bangladeshi & $(0.78 \%)$ & $(0.77 \%)$ \\
& 4,860 & 4,018 \\
Indian & $(0.86 \%)$ & $(0.86 \%)$ \\
& 11,918 & 12,104 \\
Pakistani & $(2.12 \%)$ & $(2.59 \%)$ \\
& 13,213 & 11,471 \\
Chinese & $(2.35 \%)$ & $(2.45 \%)$ \\
& 1,558 & 1,516 \\
Other & $(0.28 \%)$ & $(0.32 \%)$ \\
White & 11,374 & 7,947 \\
Total & $(2.02 \%)$ & $(1.70 \%)$ \\
\hline \hline
\end{tabular}

Note:

1. Percentage of sample in parentheses. Numbers refer to state school pupils only.

\section{Test score data}

Table 2 provides a summary of the Key-stage scores for cohorts 1 and 2. In Key-stages 1 to 3, these refer to the simple average of scores in assessments for English, Maths and Science. At Key-stage 4 we take the total GCSE points score (though we do consider another variant based on the pupil's best eight subjects below). There are two immediate points from Table 2. First, the tests are scored somewhat differently at each level. Second, the big change is from 
KS3 to KS4 when the mean and median are substantially higher, and more importantly the standard deviation increases three-fold. This is potentially problematic as we want to compare progress through the Key-stages of the different groups.

Table 2: Summary of overall key-stage scores for cohorts 1 and 2

\begin{tabular}{llllll}
\hline & Cohort 1 & \multicolumn{5}{c}{ Cohort 2 } \\
& Key-stage 1 & Key-stage 2 & Key-stage 2 & Key-stage 3 & Key-stage 4 \\
\hline Mean & 14.56 & 27.47 & 25.91 & 33.35 & 41.50 \\
Median & 15 & 27 & 27 & 33 & 43 \\
Range & 0 to 25.5 & 15 to 39 & 15 to 39 & 15 to 57 & 0 to 137 \\
$\begin{array}{l}\text { Standard } \\
\text { Deviation }\end{array}$ & 3.64 & 4.17 & 4.15 & 6.46 & 18.87 \\
\hline \hline
\end{tabular}

Our main approach to this is to standardize each Key-stage score. That is, separately for each cohort at each Key-stage, we subtract the cohort-Key-stage mean score from each pupil's score and divide by the cohort-Key-stage standard deviation. This means that these z-scores are comparable across cohort and Key-stages, and means that the analysis is purely about relative progress within the cohorts. We also look at ranks in the initial analysis reported below.

\section{Neighbourhood Data}

Using pupils' postcodes, we match in data on neighbourhoods. These measures of neighbourhood fulfil two roles. First, they provide an additional factor proxying the individual's own household context; second, they measure the deprivation of the neighbourhood itself, and hence may relate to the focus individual's (home) peer group. We have data at two different scales. Firstly, we use the Index of Multiple Deprivation (IMD) produced by the Office of the Deputy Prime Minister. ${ }^{4}$ This is a ward ${ }^{5}$ level dataset that ranks every ward in England on a range of criteria. These criteria are: Income (25\%); Employment (25\%); Health deprivation and disability (15\%); Education, skills and training $(15 \%)$; Housing (10\%); and Geographical access to services (10\%). We use the overall measure that averages these with the weights shown.

\footnotetext{
4 For more information see http://www.odpm.gov.uk/stellent/groups/odpm_urbanpolicy/documents/page/odpm_u rbpol 608140.hcsp.

5 A ward is a small geographical unit, containing on average around 12,000 people.
} 
Secondly, we have matched pupil's postcodes to the Mosaic classification6 of that address. Mosaic classification is a postcode level dataset that categorises each postcode in the UK into one of 61 different types on the basis of demographics, socio-economics and consumption, financial measures, and property characteristics and value. Over 400 variables are used to construct these classifications and as such this provides a rich picture of pupil's neighbourhoods at a very local level.

\section{Modelling Framework}

We adopt a human capital approach, and assume an individual's test score (y) depends on their human capital $^{7}(h)$ plus some noise $(e): y=h+e$. The formation of human capital is complex, but our data force us to take a simple approach. In the results, we first look at levels of attainment at different Key Stages. Given the cumulative nature of human capital formation, the role of current dated variables should be interpreted as proxying the history of these variables. We model the level of human capital for pupil $i$ at Key Stage $t$ as:

$h_{i t}=\eta_{t}+\Sigma_{j} \gamma_{j t} X_{i j}+\Sigma_{l} \alpha_{l t} Z_{i l}+\Sigma_{m} \beta_{m t} \varepsilon_{i m}$

We allow all the coefficients to vary with Key Stage ${ }^{8}$ (age). Measured personal characteristics (such as gender and within-year age) are in $X$, and measured family characteristics (such as poverty) are in $Z$. The final term $\Sigma_{m} \beta_{m t} \varepsilon_{i m}$ represents the myriad influences on human capital that we do not include because we have no measures of them. These include: parental interest in education, parental expectations of the child, parental ability to help with learning, parental resources; the pupil's aspirations and role models, the pupil's effort and work ethic, attitude to homework, happiness at school, degree of engagement with school life, natural ability; feelings of support or harrassment from peers, peers' attitudes to learning, peers' ability; teacher expectations of the pupil, teacher ability and effort; opportunities outside school for the pupil and so on. Any of these factors may be correlated with a pupil's ethnicity, and it

6 For more information see http://www.experian.co.uk/business/products/data/113.html.

$7 \quad$ We generalise this below.

8 As we noted above, the potentially time-varying variables (FSM, SEN and neighbourhood) are only reported in our data for one date, 2002. This means that the in the regressions for the earlier tests, the value of the coefficient on, say, FSM, reflects two things: that disadvantage may impact differently on attainment at different ages, and that $\mathrm{FSM}_{2002}$ is only proxying $\mathrm{FSM}_{2000}$ and $\mathrm{FSM}_{1997}$ 
is essentially the role of the ethnic group dummy variables we include in estimation to pick up these effects. Thus the coefficient on an ethnic group dummy summarises the correlation of membership of that ethnic group with the list of omitted variables $\left(\varepsilon_{m}\right)$ weighted by their impact on human capital $\left(\beta_{m}\right)$.

In most of the analyses below, we do not include characteristics of pupils' schools. A straightforward interpretation of such variables if included would require the assumption that pupils are randomly allocated to schools. This is very unlikely to be true, and particularly in a study of ethnic differences, does not seem a sound assumption to rely on. Therefore, for the bulk of our results not conditioning on school effects, the interpretation of (say) FSM or ethnicity is that it includes both the direct impact of that characteristic on test score, plus the indirect effect on school quality and the impact of that quality on test score. Put another way, we exploit variation across schools (as this is part of the story) as well as within schools. We briefly consider the role of school fixed effects in Table 14.

The equation we estimate for attainment levels is:

$y_{i t}=\Sigma_{g} \pi_{g t} I(\text { ethnic group })_{i}+b_{1 t} \cdot$ gender $_{i}+b_{2 t} \cdot$ age $_{i}+b_{3 t} \cdot \mathrm{FSM}_{i}+b_{4 t} \cdot \mathrm{SEN}_{i}+\Sigma_{n}$ $b_{5 n t} . I\left(\mathrm{n}^{\prime} \text { hood }\right)_{i}$

We also look at a pupil's progress over the Key Stages, referred to as valueadded. We measure progress through the tests following the Department for Education and Skills approach to value added. This involves taking all pupils who achieved a particular grade at (say) KS2, and computing the average KS4 score for that group. An individual pupil's value added from KS2 to KS4 is then the difference between her own grade and that average for her group. This implies two things: value-added is completely relative, and some scores will be negative; secondly, mean value added is by construction zero at each KS level. This can be written as follows $v_{i t} \equiv y_{i t}-E\left(y_{i t} \mid y_{i t-1}=Y\right)$, where $v$ is value-added, $i$ is a pupil, $t$ a Key Stage, and the mark $Y$ defines one group from the previous Key Stage. So pupil $i$ will achieve positive value-added if she is more able or has more positive factors than others who scored the same mark $Y$ at the previous key-stage.

Finally, we consider a generalisation of the simple model above to allow differences between ethnic groups $(g)$ in the mapping from human capital to test score: $y=a_{g} h+e$, and $a_{g 1} \neq a_{g 2}$. There are two possible reasons group-specific variation might arise. First, the nature of the curriculum or testing format might favour particular groups; second, marking of the tests may favour some groups, 
perhaps through teacher bias. In general the parameter $a$ is not identified, but we can discuss the impact of any such group differences. With both of these factors there are good reasons to assume that any group differences in $a$ are constant over an individual's school career. Since the curriculum and Key Stage tests are all designed centrally, any relevant features will carry through all the Key Stages considered here. Secondly, for our analysis of secondary school tests, we use data from remotely marked tests, not teacher assessments. Bias is feasible from ethnicly-identifying names on scripts, but the point is that this is equally true for Key Stage tests at 11, 14 and 16.

\section{Results I: The Dynamics of Attainment}

We present the results in two parts. In this section we establish the facts on the evolution of attainment for our two cohorts. In the next section we investigate a number of possible explanations for the facts. We first present summary results from the distribution of individual's test scores, standardised as above, but otherwise just the raw data. We then introduce control variables for the individual and examine the resulting conditional attainment gaps. We cut the data longitudinally and examine value-added (defined below) by ethnicity. We also present results at the lower quantiles of the attainment distribution. Finally, we quantify the impact of changes through the schooling process on chances of progressing beyond compulsory schooling.

\section{Raw Attainment Gaps}

Before presenting the results, it is interesting to consider what changes we might expect in the relative attainment of minority students during schooling. We discussed the possible reasons lying behind score gaps above, but here we are also interested in the change in the gap over a student's school career. It may be that most of the influence of disadvantage comes in a student's early years, and so there is relatively little change once the students enter schooling. Or it may be that ethnic minority students typically go to worse schools, and so we would expect them to fall further behind as schooling continues. Or it may be that language is an important issue and increasing fluency brings substantial gains in performance. With these possibilities in mind, we now turn to the evidence.

We present the results graphically. Figure 1 shows the mean standardised test scores at each age by ethnicity. We split the figure into two panels for easier interpretation, and repeat the line for white students in each. The group mean standardised score is plotted on the vertical axis, against the age that the test was taken on the horizontal axis. The run of test scores for each cohort-group is shown as a line. We do not represent variation around the mean on the graph, 
but provide age-group specific standard deviations below (Table 3) along with other quantile analysis.

Table 3: Mean and standard deviations ${ }^{1}$ of overall key-stage score for cohorts 1 and 2

\begin{tabular}{llllll}
\hline \hline \multirow{2}{*}{ Ethnicity } & Cohort 1 & \multicolumn{5}{l}{ Cohort 2 } \\
& Key-stage 1 & Key-stage 2 & Key-stage 2 & Key-stage 3 & Key-stage 4 \\
\hline Black & 14.12 & 26.85 & 24.15 & 30.79 & 40.09 \\
African & $(3.90)$ & $(4.12)$ & $(4.42)$ & $(6.60)$ & $(17.65)$ \\
Black & 14.06 & 26.28 & 24.25 & 29.89 & 33.57 \\
Caribbean & $(3.61)$ & $(4.12)$ & $(4.06)$ & $(5.93)$ & $(16.88)$ \\
Black Other & 13.96 & 26.68 & 24.64 & 30.78 & 35.49 \\
& $(3.66)$ & $(4.13)$ & $(4.10)$ & $(6.22)$ & $(18.27)$ \\
Bangladeshi & 12.60 & 26.18 & 23.70 & 29.96 & 40.13 \\
& $(3.88)$ & $(4.25)$ & $(4.38)$ & $(6.35)$ & $(17.98)$ \\
Indian & 14.64 & 27.84 & 25.41 & 33.63 & 47.23 \\
& $(3.55)$ & $(3.97)$ & $(4.06)$ & $(6.39)$ & $(17.35)$ \\
Pakistani & 12.84 & 25.55 & 23.24 & 29.57 & 37.43 \\
& $(3.87)$ & $(4.45)$ & $(4.30)$ & $(6.37)$ & $(17.99)$ \\
Chinese & 15.11 & 29.44 & 26.92 & 36.42 & 53.71 \\
& $(3.72)$ & $(3.71)$ & $(4.07)$ & $(6.49)$ & $(17.68)$ \\
Other & 14.40 & 27.65 & 25.6 & 33.2 & 42.8 \\
& $(3.90)$ & $(4.22)$ & $(4.33)$ & $(6.81)$ & $(19.63)$ \\
White & 14.61 & 27.55 & 26.08 & 33.57 & 41.58 \\
& $(3.61)$ & $(4.15)$ & $(4.09)$ & $(6.40)$ & $(18.90)$ \\
\hline \hline
\end{tabular}

Notes:

1. Standard deviations reported in parentheses. 
Figure 1: Raw standardised values of key-stage ${ }^{1}$ scores through time for cohorts 1 and 2 by ethnicity
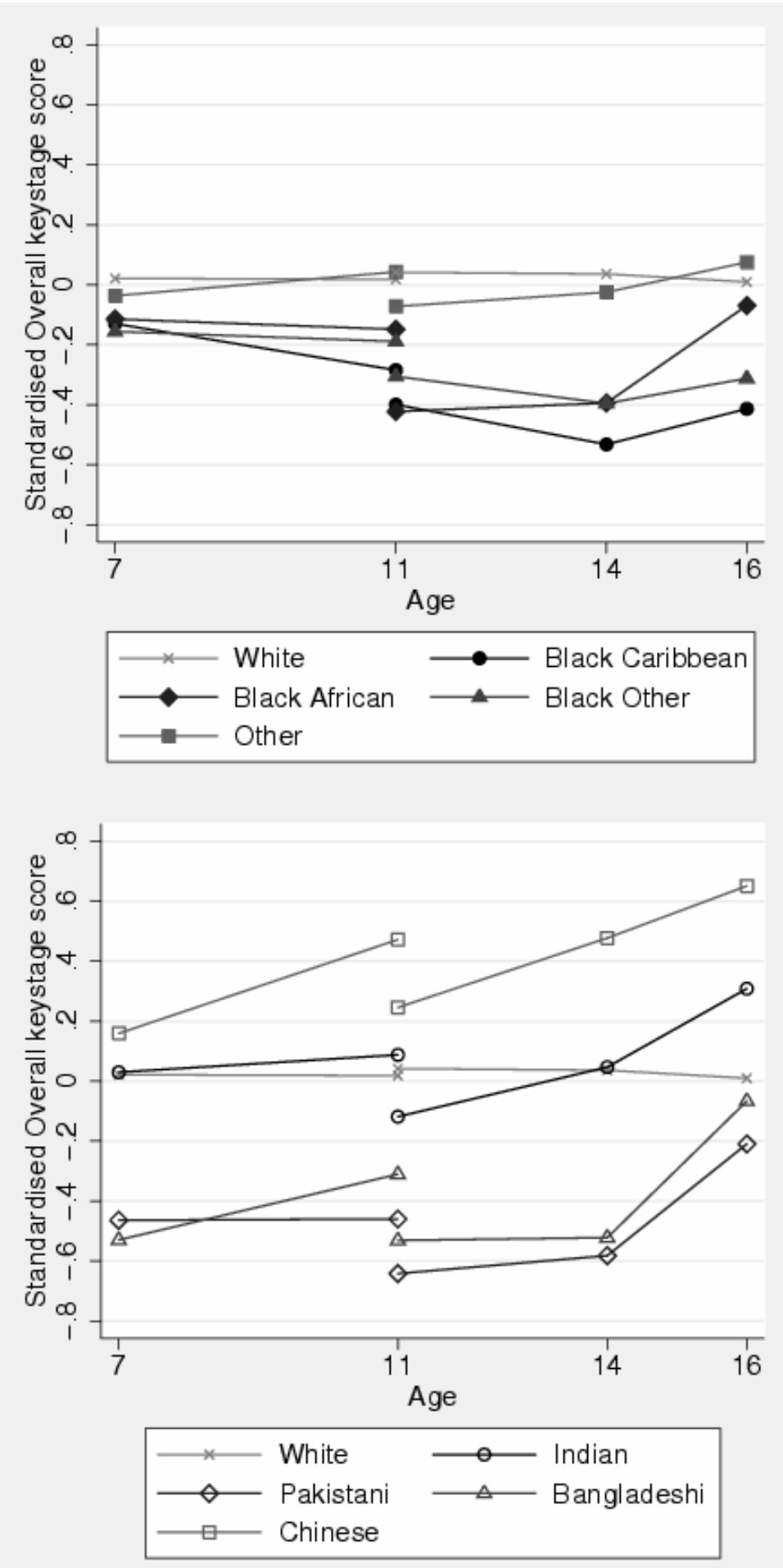

Notes:

1. Key-stage 1 assessment takes place at age 7, key-stage 2 at age 11, key-stage 3 at age 14 and key-stage 4 at age 16 . 
There are a number of things to see in the Figure. First, the line for white pupils is very close to zero and very flat, the result of our use of standardised scores and the fact that white pupils are the overwhelming majority. Second, the age 11 test scores for the more recent cohort (C1) are higher than the age 11 test scores for the earlier cohort (C2) for all but the white groups. This implies that the overall progress through time from 1997 to 2002 that had a greater impact on raising KS2 test scores for minorities. Turning now to the main focus of interest, unsurprisingly we see different patterns for different ethnic groups. Scores for all three black groups decline relative to whites' in the primary school cohort, and in the first three years of secondary schooling. However, between ages 14 and 16 (KS3 to GCSEs), all three groups show a substantial rise. This is particularly striking for pupils of Black African heritage, who after being 0.4 SDs (standard deviations) below white pupils at age 14 are almost equal by age 16. For Black Caribbean pupils also, while the $14-16$ gain is lower, it wipes out the loss between age 11 and 14. For all groups in the first panel, and in both cohorts, pupils from minority backgrounds start with scores below those of white pupils. In the second panel, we see a different picture for ethnic Asian groups. Students of Chinese ethnicity start at higher levels than whites and pull further away during schooling. They show the highest mean attainment of any group across both primary and secondary schools. The test scores of students with Indian ethnicity are essentially indistinguishable from those of their white peers in the primary school cohort. Starting secondary school, Indian students have scores on average about 0.1 SDs below whites. By the end of secondary school, five years later, they achieve scores 0.3 SDs above whites. Pakistani and Bangladeshi students have relatively low scores in the primary school cohort. In the secondary school cohort, they also arrive with low scores, but show very substantial gains, of the order of 0.4 SDs. One of the overall patterns that we highlight from Figure 1 is that all ethnic minority groups make substantial progress relative to white students between the ages of 14 (KS3) and 16 (GCSE).

An alternative way of presenting the data such that the scales are the same at each age is to look at ranks. Each pupil is assigned their rank in the distribution at each age, and the group average rank is tracked over the window. ${ }^{9}$ The result of doing this is shown in Figure 2, and shows the same qualitative pattern as the standardised test scores.

$9 \quad$ With tied scores we randomly assigned observations a unique rank. 


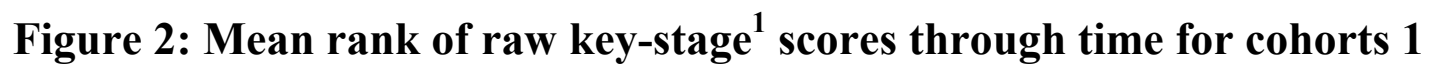
and 2 by ethnicity
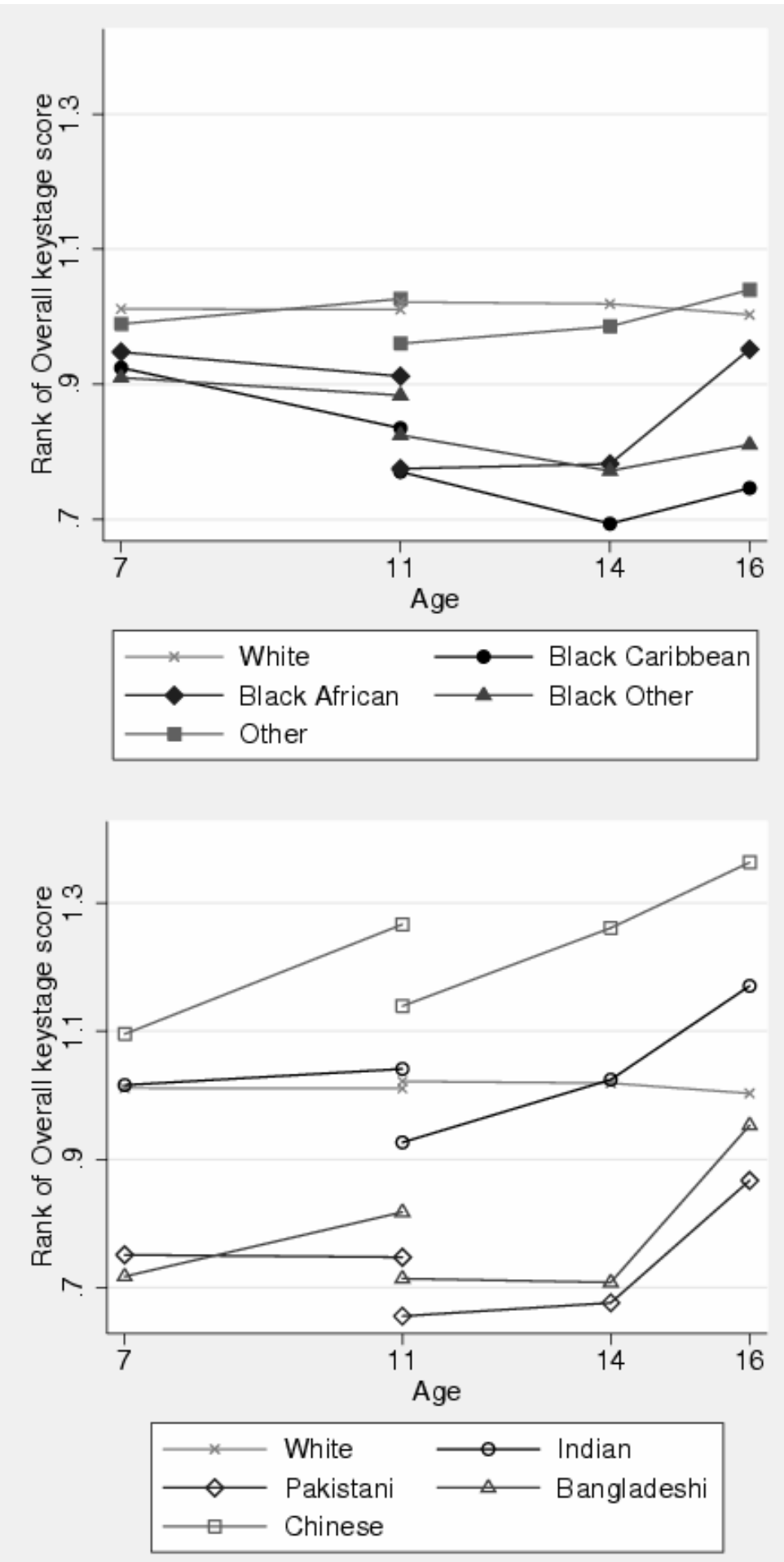

Notes:

1. Key-stage 1 assessment takes place at age 7, key-stage 2 at age 11, key-stage at age 14 and key-stage 4 at age 16 . 
Another alternative is to start from the relatively discrete nature of KS2 scores (we have 17 distinct values in the mean KS2 score), and equivalently discretise the GCSE scores. We split the GCSE score distribution into 17 groups, of roughly equal size as the KS2 bands ${ }^{10}$ and examine transitions across these bands over secondary school. The results are in Table 4. Overall, more students move to higher groups than to lower, ${ }^{11}$ and, as the biggest group, so do white students: the difference between those improving (51\%) and declining $(38 \%)$ is 13 percentage points. Turning to the minority ethnic groups, we see a similar pattern again. Students with Black Caribbean and other Black heritage show slightly more students moving to lower groups than higher. But Black African students have far greater percentages moving to higher than lower groups, an excess of 32 percentage points. The same is true for Bangladeshi (35 points), Indian (51 points), Pakistani (26 points) and Chinese (64 points) students.

To summarise so far, dealing with the differences in measurement over the cohort in three different ways (normalised z-scores, ranks, discrete bands), we find the same pattern of relative progress. We use the normalised z-scores as the basis for the rest of the analysis.

Figure 3 presents the same information, split by poverty status, measured by free school meal eligibility. ${ }^{12}$ It is clear that mean scores are lower for all groups among pupils from poor families - all the lines are shifted down relative to nonpoor pupils. Otherwise many of the same patterns carry through. The gap at age 16 between Indian, Pakistani and Bangladeshi students is lower among poor students than non-poor. One striking fact is that poor white students are the lowest performing of all groups at age 16, showing a substantial deterioration in their relative scores through secondary school.

10 We keep tied scores together, rather than split across cells and this marginally changes cell sizes.

11 This is perfectly possible - it is not the case that the same fractions need to go up as down. Nor does it necessarily say anything about overall pupil progress, it is simply due to the patterns of relative progress. For example, suppose we split pupils into ten equal groups. Suppose that all in the bottom nine groups improve one group, and all in the top group fall to the lowest group. Then we would see $90 \%$ of pupils moving to higher groups.

12 Note that this is poverty status in 2002 , that is, the end date of each cohort. 
Figure 3a: Raw values for overall standardised values of key-stage ${ }^{1}$ scores through time for cohorts 1 and 2 by ethnicity: Pupils with FSM status
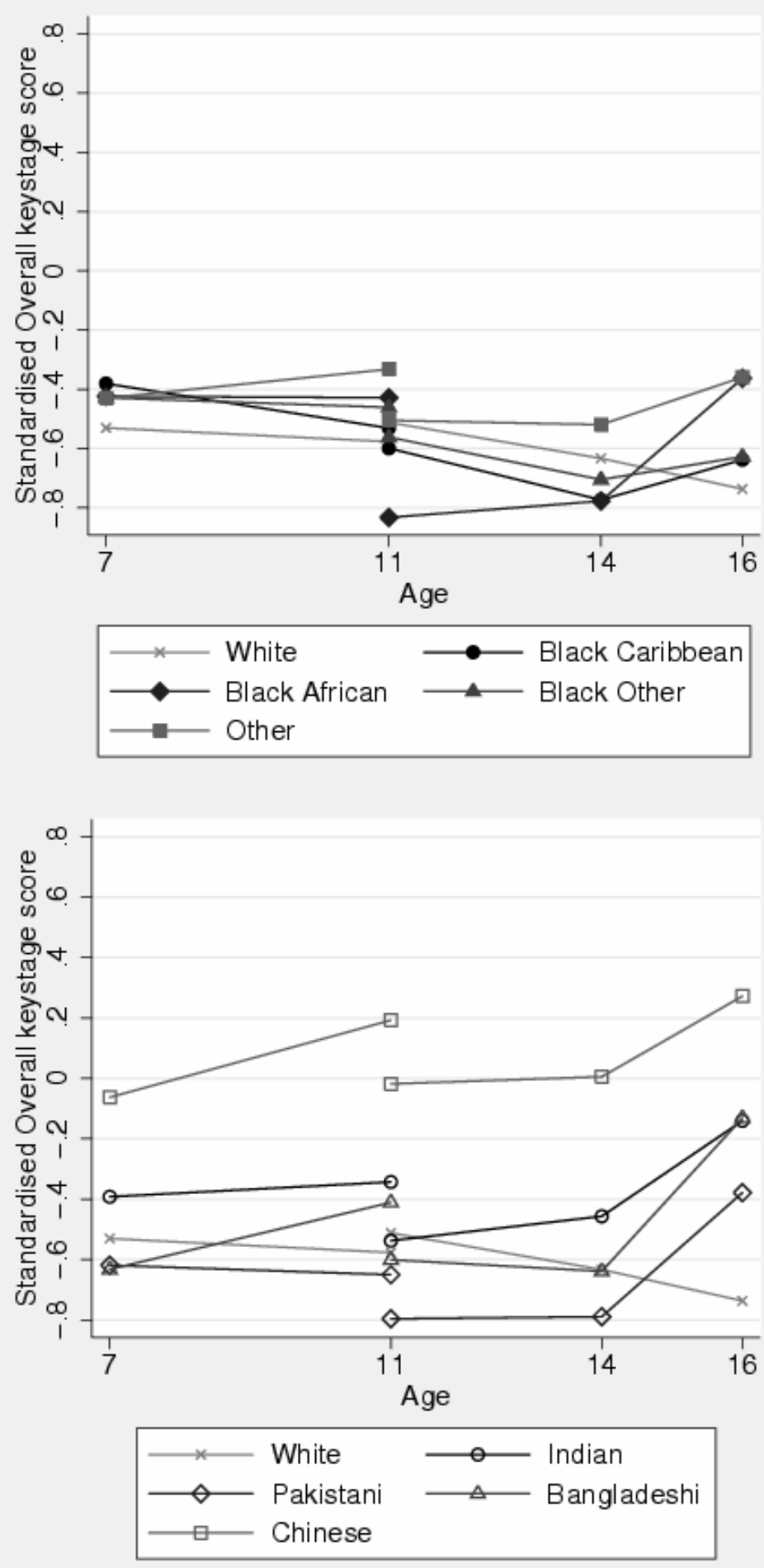

Notes:

1. Key-stage 1 assessment takes place at age 7, key-stage 2 at age 11, key-stage 3 at age 14 and key-stage 4 at age 16. 
Figure 3b: Raw values for overall standardised values of key-stage ${ }^{1}$ scores through time for cohorts 1 and 2 by ethnicity: Pupils without FSM status
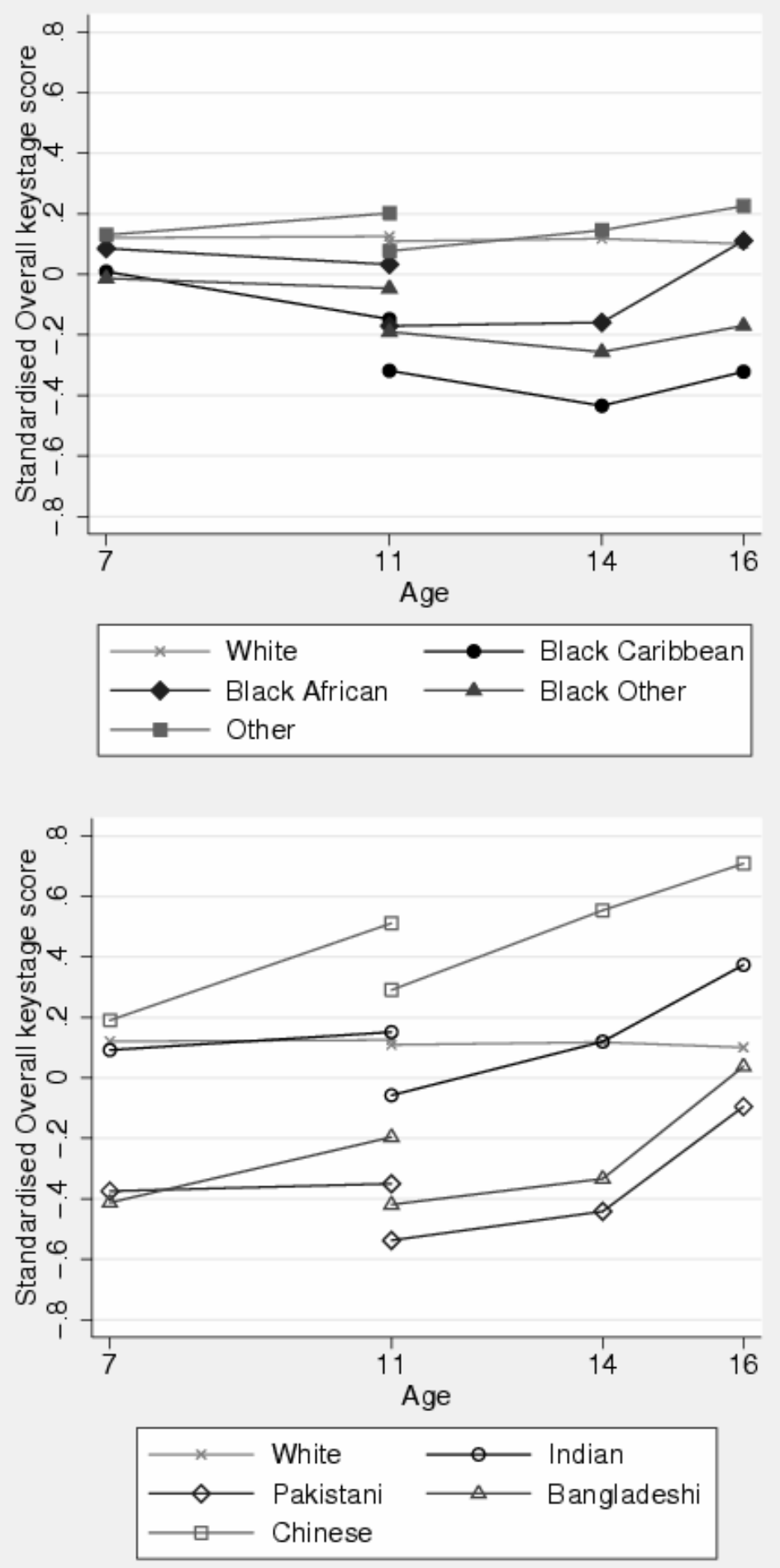

Notes:

1. Key-stage 1 assessment takes place at age 7, key-stage 2 at age 11, key-stage 3 at age 14 and key-stage 4 at age 16 . 
Table 4: Percentage of pupils moving key-stage group between key-stage 2 and key-stage 4 by ethnicity ${ }^{1}$

\begin{tabular}{lccc}
\hline \hline Ethnicity & $\begin{array}{c}\text { Percentage } \\
\text { staying in same } \\
\text { group }\end{array}$ & $\begin{array}{c}\text { Percentage } \\
\text { moving to a } \\
\text { higher group }\end{array}$ & $\begin{array}{c}\text { Percentage } \\
\text { moving to a lower } \\
\text { group }\end{array}$ \\
\hline Black African & 429 & 2,343 & 1,100 \\
Black Caribbean & $(11.08 \%)$ & $(60.51 \%)$ & $(28.41 \%)$ \\
Black Other & 724 & 2,457 & 3,170 \\
Bangladeshi & $(11.40 \%)$ & $(38.69 \%)$ & $(49.91 \%)$ \\
Indian & 420 & 1,480 & 1,697 \\
Pakistani & $(11.68 \%)$ & $(41.15 \%)$ & $(47.18 \%)$ \\
& 424 & 2,498 & 1,096 \\
Chinese & $(10.55 \%)$ & $(62.17 \%)$ & $(27.28 \%)$ \\
& 1,129 & 8,604 & 2,371 \\
Other & $(9.33 \%)$ & $(71.08 \%)$ & $(19.59)$ \\
& 1,418 & 6,520 & 3,533 \\
White & $(12.36 \%)$ & $(56.84 \%)$ & $(30.80 \%)$ \\
& 88 & 1,199 & 229 \\
& $(5.80 \%)$ & $(79.09 \%)$ & $(15.11 \%)$ \\
\hline \hline
\end{tabular}

Notes:

1. Overall key-stage 2 score has 17 distinct values. Therefore, total GCSE (KS4) point score was split into 17 distinct groups to mimic key-stage 2 attainment. The presented figures are constructed on the basis of these key-stage 'groups' and movement between the groups between key-stages.

Figure 4 shows outcomes separately for male and female students. We see the well-established gender differences in levels. But we also see that the gains among minority population pupils are stronger for female than male pupils. 
Figure 4a: Raw values for overall standardised values of key-stage ${ }^{1}$ scores $^{2}$ through time for cohorts 1 and 2 by ethnicity: For Male pupils
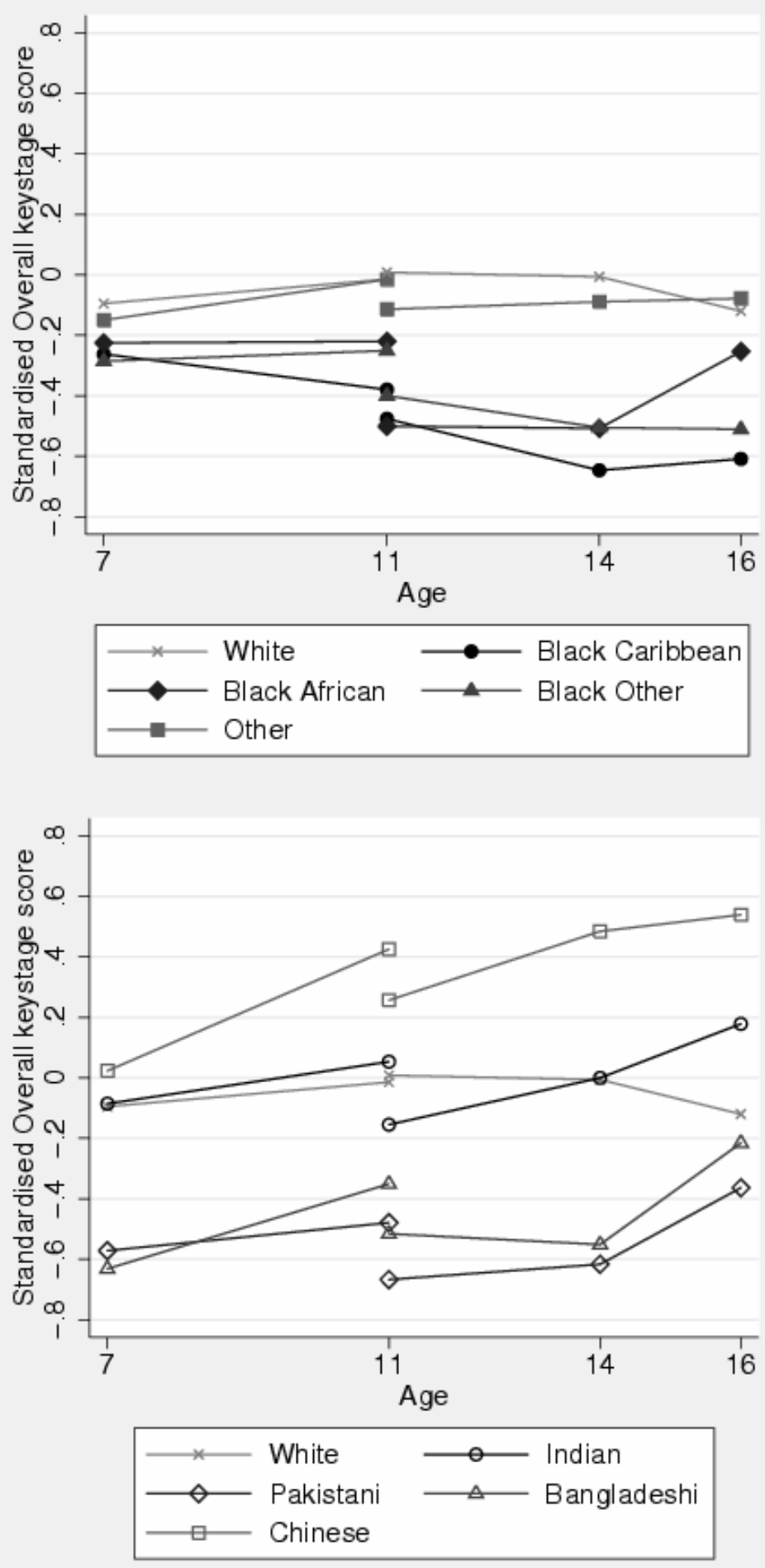

Notes:

1. Key-stage 1 assessment takes place at age 7, key-stage 2 assessment takes place at age 11, key-stage 3 at age 14 and key-stage 4 at age 16 . 
Figure 4b: Raw values for overall standardised values of key-stage ${ }^{1}$ scores $^{2}$ through time for cohorts 1 and 2 by ethnicity: For female pupils
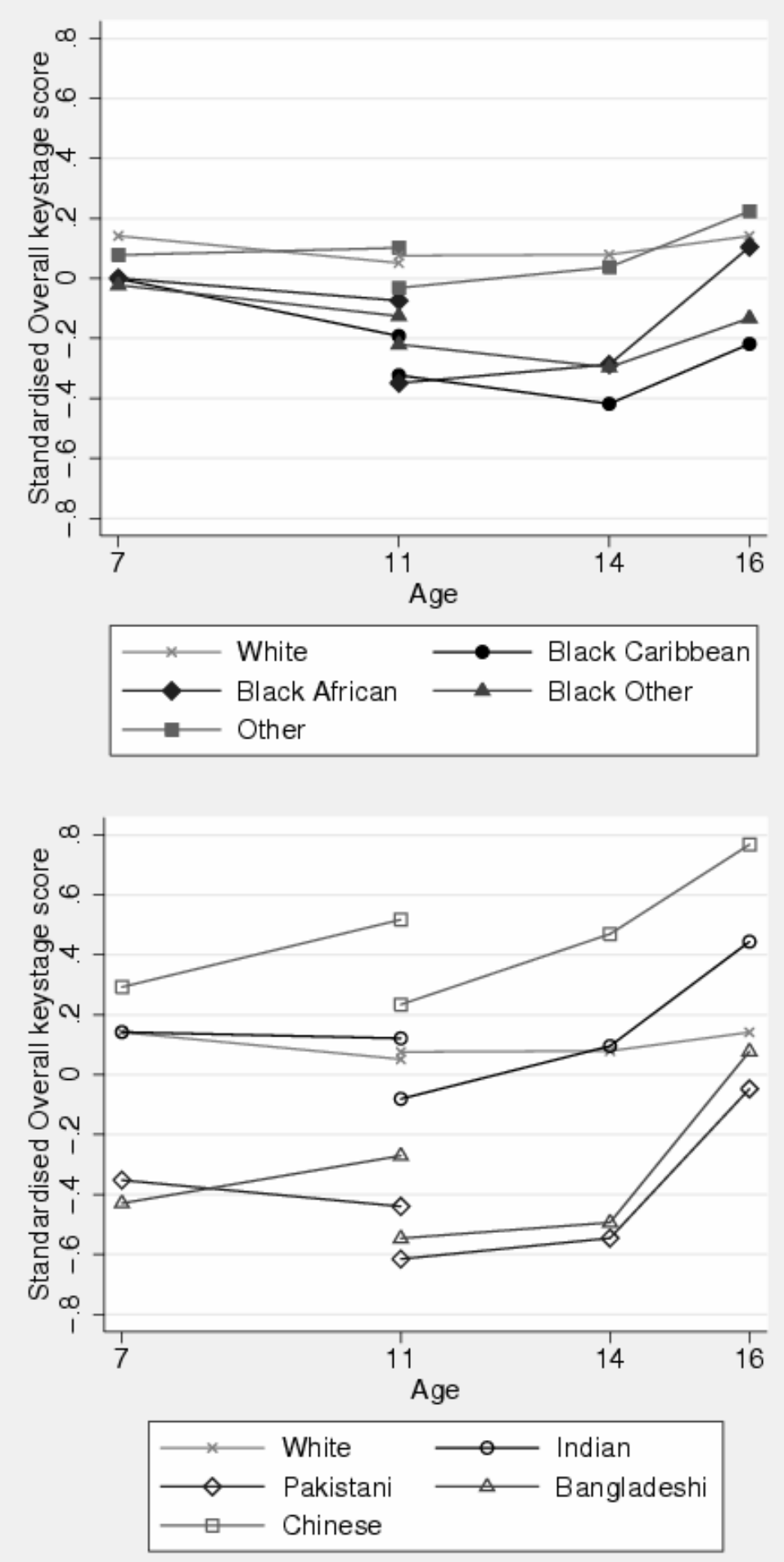

Notes:

1. Key-stage 1 assessment takes place at age 7, key-stage 2 assessment takes place at age 11, key-stage 3 at aged 14 and key-stage 4 at age 16 . 
In Table 3 we present the mean raw (un-standardised) scores by age and ethnicity, and standard deviations. The variance in outcomes across ethnic groups at each stage is very similar.

Finally in this section, we return to the issue raised in the Data section on the pupils omitted from the analysis through our use of balanced panel. We argued above that this is not much of an issue for any groups other than Black African heritage students. In Appendix Table 2, we compare the scores of the cohort 2 students used in the analysis with all students who took each test, and compute the percentage difference for KS4. We can see that again, for all but this same group, the differences are minor. For Black African heritage students, the difference at KS4 is $10 \%$ - the analysis cohort students averaging 40.09 relative to 36.22 for all such students. The gap is the same way, but lower at KS3 (4.4\%) and at KS2 $(0.26 \%)$. Thus we need to bear in mind that the KS4 scores of this ethnic group are slightly unrepresentative of the total of that group taking that exam at that time.

However, in terms of one of the most interesting findings above, the balanced panel under-estimates the full population facts. We observed a substantial acceleration in test score gains from $(\mathrm{KS} 2 \rightarrow \mathrm{KS} 3)$ to $(\mathrm{KS} 3 \rightarrow \mathrm{KS} 4)$ for this group. Appendix Table 3 shows that comparing the cohort with the population on this feature, the whole population data shows an even greater acceleration. The Table also shows, that with the exception of the Other ethnicity group, the differences between the cohort and the full population are minor for all other groups.

\section{Conditional Attainment Gaps}

Test score performance is likely to depend on a number of individual characteristics, as well as school factors and possibly neighbourhood factors. We include controls for gender, poverty, within-year age, special educational needs status, and the two characterisations of neighbourhood introduced above.

In Table 5 we show the impact on the estimated ethnicity factors of adding these controls to the age 16 regression. Column 1 has no controls and so simply replicates the raw figures shown in Figure 1. We add individual controls in Column 2. Unsurprisingly, these add a lot to the explanatory power of the model - raising the $\mathrm{R}^{2}$ from 0.008 to 0.251 . This change in the $\mathrm{R}^{2}$ makes an important point: ethnicity itself explains very little of the difference between scores, less than $1 \%$. But including gender and poverty and other variables raises this to $25 \%$. The coefficients on ethnic identities also change considerably. Controlling for these personal characteristics, the coefficients on all but Indian and Chinese groups increase. For Black African, Bangladeshi and Pakistani students, this switches the sign to positive - that is, they score more 
highly than equivalent whites. For Black Caribbean and other Black students, the coefficient is less negative (by 0.3 SDs for Black Caribbean heritage students). For students with Indian and Chinese ethnicity, a high positive coefficient falls slightly. Given that these groups are not much different to whites in terms of poverty this is as expected. Adding in the two different neighbourhood characteristics accentuates this change. Taking column 3, with the ward-level Index of Multiple Deprivation, shows that only Black Caribbean pupils now show a negative coefficient, and at $0.03 \mathrm{SDs}$, this is small. Black African pupils show a conditional gain over whites of 0.33 SDs. Pupils of all the Asian ethnicities are estimated to achieve substantially higher scores than whites, conditional on the individual and neighbourhood factors. The differences in the ethnicity coefficients between columns 3 and 4 arise from the difference in scale between the IMD at ward level, and the Mosaic classification at postcode level.

We have re-run the analysis above in different ways. ${ }^{13}$ First, we consider only pupils in schools in non-selective LEAs ${ }^{14}$ - that is, dropping the few remaining LEAs with ability selection (grammar schools). Second, we analyse capped GCSE scores, the sum of scores on the student's best 8 GCSEs, thus standardising for any differences in the number of exams taken. In both of these cases, the results are qualitatively the same as shown above. Third, we cluster the standard errors at school level; this has little impact on the significance of the key variables.

13 Results available from the authors.

14 These form the large majority of all LEAs. 
Table 5: Regressions of standardised values of Key-stage 4 test scores (Total GCSE point score) for cohort 2

\begin{tabular}{|c|c|c|c|c|c|}
\hline & Explanatory Variables & 1 & 2 & 3 & 4 \\
\hline \multirow{16}{*}{ Ethnic Group } & \multirow{2}{*}{ Black African } & -0.079 & 0.169 & 0.308 & 0.215 \\
\hline & & $(4.91)^{* *}$ & $(11.99)^{* *}$ & $(22.03)^{* *}$ & $(15.34)^{* *}$ \\
\hline & \multirow{2}{*}{ Black Caribbean } & -0.423 & -0.190 & -0.045 & -0.091 \\
\hline & & $(33.73)^{* *}$ & $(17.24)^{* *}$ & $(4.09)^{* *}$ & $(8.37)^{* *}$ \\
\hline & \multirow{2}{*}{ Black Other } & -0.322 & -0.120 & 0.003 & -0.035 \\
\hline & & $(19.36)^{* *}$ & $(8.24)^{* *}$ & $(0.18)$ & $(2.49)^{*}$ \\
\hline & \multirow{2}{*}{ Bangladeshi } & -0.076 & 0.275 & 0.484 & 0.307 \\
\hline & & $(4.86)^{* *}$ & $(19.71)^{* *}$ & $(34.64)^{* *}$ & $(21.76)^{* *}$ \\
\hline & \multirow{2}{*}{ Indian } & 0.299 & 0.273 & 0.376 & 0.288 \\
\hline & & $(32.65)^{* *}$ & $(34.04)^{* *}$ & $(47.52)^{* *}$ & $(34.20)^{* *}$ \\
\hline & \multirow{2}{*}{ Pakistani } & -0.219 & 0.019 & 0.222 & 0.093 \\
\hline & & $(23.34)^{* *}$ & $(2.26)^{*}$ & $(26.82)^{* *}$ & $(9.97)^{* *}$ \\
\hline & \multirow{2}{*}{ Chinese } & 0.642 & 0.603 & 0.639 & 0.589 \\
\hline & & $(25.12)^{* *}$ & $(26.85)^{* *}$ & $(28.82)^{* *}$ & $(27.76)^{* *}$ \\
\hline & \multirow{2}{*}{ Other } & 0.066 & 0.166 & 0.230 & 0.182 \\
\hline & & $(5.85)^{* *}$ & $(16.85)^{* *}$ & $(23.57)^{* *}$ & $(19.02)^{* *}$ \\
\hline \multirow{8}{*}{$\begin{array}{l}\text { Personal } \\
\text { Characteristics }\end{array}$} & \multirow{2}{*}{ Gender (= 1 if female) } & & 0.177 & 0.182 & 0.192 \\
\hline & & No & $(68.84)^{* *}$ & $(72.00)^{* *}$ & $(79.06)^{* *}$ \\
\hline & \multirow{2}{*}{ Free School Meal Status (= 1 if has FSM) } & No & -0.605 & -0.448 & -0.333 \\
\hline & & \multirow{3}{*}{ No } & $(154.37)^{* *}$ & $(112.32)^{* *}$ & $(84.86)^{* *}$ \\
\hline & \multirow{2}{*}{ SEN (=1 if SEN without statement) } & & -1.009 & -0.977 & -0.915 \\
\hline & & & $(270.61)^{* *}$ & $(265.40)^{* *}$ & $(258.46)^{* *}$ \\
\hline & SEN (=1 if SEN with statement) & No & $\begin{array}{l}-1.297 \\
(14841) * *\end{array}$ & -1.275 & -1.211 \\
\hline & Month of Birth & No & $\begin{array}{c}(148.41)^{* n} \\
\text { Yes }\end{array}$ & $\begin{array}{c}(14 / .60)^{n *} \\
\text { Yes }\end{array}$ & $\begin{array}{c}(140.31)^{*} \\
\text { Yes }\end{array}$ \\
\hline Neighbourhood & Index of Multiple Deprivation & No & No & Yes & No \\
\hline Characteristics & Mosaic Classification & No & No & No & Yes \\
\hline & & 0.008 & 0.251 & 0.293 & 0.346 \\
\hline Observations $^{1}$ & & 467,463 & 467,144 & 456,000 & 461,461 \\
\hline
\end{tabular}

Absolute values of t-statistics in parentheses

* Significant at $5 \% \quad * *$ Significant at $1 \%$

Notes: 1 Different numbers of observations for different specifications is due to missing data on some controls. 
We adopt specification 4 of Table 5 and run this set of controls on tests at all ages. The results are in Table 6 . Note that for both cohorts, the controls explain a reasonable fraction of the variation in attainment scores. Poverty has a significant, negative, effect at all test ages. One point to deal with here is that while we are running these regressions on the different Key Stages (and therefore different dates), we only know the values of FSM, SEN and neighbourhood at one date, 2002. In the regressions for the earlier tests, the value of the coefficient on, say, FSM, reflects two things: that disadvantage may impact differently on attainment at different ages, and that FSM2002 is only proxying FSM2000 and FSM1997. Thus the fact that FSM is increasing in importance through both cohorts could reflect a real phenomenon, or it could simply be that the lower coefficients from the earlier ages result from the same impact on attainment, attenuated by measurement error. The evolution of the gender coefficients is interesting. In the secondary school cohort, it shows lower attainment by females in the 1997 age 11 tests, increasing to about zero in age 14 to significantly positive in age 16 tests, worth almost 0.2 SDs. This change through time is now well known. Interestingly, in the primary school cohort, the temporal pattern is the reverse.

These regressions produce a set of conditional ethnicity effects comparable to the unconditional effects in Figure 1, and we present the ethnicity coefficients from Table 6 graphically in Figure 5. The figure does not show standard error bands, but these are available in the table. Since 'white' was the omitted group in the regressions, the lines should be compared to zero to judge relative progress. In some ways the pattern is similar to that of Figure $1,{ }^{15}$ but if anything some of the striking features of Figure 1 are exaggerated here. In fact over secondary schooling, the attainment of all ethnic minority groups improves relative to whites. Some ethnic groups make very substantial gains relative to whites during secondary school. Pupils with Bangladeshi ethnicity for example, start secondary school 0.3 SDs below whites, but finish 0.32 SDs above. This gain of 0.6 SDs equates to about $10 \mathrm{GCSE}$ points. This is equivalent to changing five $\mathrm{C}$ grades all to A. Similarly, pupils with Black African heritage improve from -0.26 SDs at age 11 to +0.23 SDs at age 16. Students with Black Caribbean backgrounds and other Black students remain on average below their white peers at age 16, although the gap now is less than 0.1 of an SD. The situation is more mixed in the primary school cohort, with students of Asian ethnicity generally gaining, but students with Black heritage losing ground. A

15 This is only partly because we do not have time-varying poverty, neighbourhood or SEN data. If we imposed poverty to have the same effect at all ages, then with a single time observation on these, the pattern would be exactly the same, though shifted up or down. But we do allow these factors to have changing effects, and this in principle allows for a very different pattern. 
further feature to note is that the strongest gain in secondary school is again between 14 and 16. This is true for all groups, but especially Bangladeshi, Pakistani and Black African students. We return to why this might be so below.

Table 6: Regressions of standardised values of overall key-stage score ${ }^{1}$

\begin{tabular}{|c|c|c|c|c|c|}
\hline \multirow{2}{*}{$\begin{array}{l}\text { Explanatory } \\
\text { variable }\end{array}$} & \multicolumn{2}{|c|}{ Cohort 1} & \multicolumn{3}{|c|}{ Cohort 2} \\
\hline & Age $7^{2}$ & Age $11^{3}$ & Age $11^{3}$ & Age $14^{4}$ & Age $16^{5}$ \\
\hline Black African & $\begin{array}{c}0.038 \\
(3.45)^{* *}\end{array}$ & $\begin{array}{l}-0.023 \\
(2.05)^{*}\end{array}$ & $\begin{array}{c}-0.257 \\
(17.63)^{* *}\end{array}$ & $\begin{array}{c}-0.118 \\
(8.38)^{* *}\end{array}$ & $\begin{array}{c}0.215 \\
(15.34)^{* *}\end{array}$ \\
\hline Black Caribbean & $\begin{array}{c}0.054 \\
(5.86)^{* *}\end{array}$ & $\begin{array}{c}-0.111 \\
(11.76)^{* *}\end{array}$ & $\begin{array}{c}-0.187 \\
(16.57)^{* *}\end{array}$ & $\begin{array}{c}-0.229 \\
(20.98) * *\end{array}$ & $\begin{array}{c}-0.091 \\
(8.37)^{* *}\end{array}$ \\
\hline Black Other & $\begin{array}{c}-0.006 \\
(0.54)\end{array}$ & $\begin{array}{c}-0.048 \\
(3.92)^{* *}\end{array}$ & $\begin{array}{c}-0.130 \\
(8.85)^{* *}\end{array}$ & $\begin{array}{c}-0.142 \\
(9.95)^{* *}\end{array}$ & $\begin{array}{l}-0.035 \\
(2.49)^{*}\end{array}$ \\
\hline Bangladeshi & $\begin{array}{c}-0.329 \\
(27.66)^{* *}\end{array}$ & $\begin{array}{c}-0.098 \\
(8.06)^{* *}\end{array}$ & $\begin{array}{c}-0.299 \\
(20.37)^{* *}\end{array}$ & $\begin{array}{c}-0.146 \\
(10.24)^{* *}\end{array}$ & $\begin{array}{c}0.307 \\
(21.76)^{* *}\end{array}$ \\
\hline Indian & $\begin{array}{c}-0.054 \\
(6.98)^{* *}\end{array}$ & $\begin{array}{l}-0.006 \\
(0.77)\end{array}$ & $\begin{array}{c}-0.183 \\
(20.87)^{* *}\end{array}$ & $\begin{array}{l}0.011 \\
(1.35)\end{array}$ & $\begin{array}{c}0.288 \\
(34.20)^{* *}\end{array}$ \\
\hline Pakistani & $\begin{array}{c}-0.296 \\
(36.52)^{* *}\end{array}$ & $\begin{array}{c}-0.278 \\
(33.49)^{* *}\end{array}$ & $\begin{array}{c}-0.448 \\
(45.99)^{* *}\end{array}$ & $\begin{array}{c}-0.286 \\
(30.33)^{* *}\end{array}$ & $\begin{array}{c}0.093 \\
(9.97)^{* *}\end{array}$ \\
\hline Chinese & $\begin{array}{l}0.006 \\
(0.28)\end{array}$ & $\begin{array}{c}0.312 \\
(15.46)^{* *}\end{array}$ & $\begin{array}{c}0.136 \\
(6.17)^{* *}\end{array}$ & $\begin{array}{c}0.392 \\
(18.29)^{* *}\end{array}$ & $\begin{array}{c}0.589 \\
(27.76)^{* *}\end{array}$ \\
\hline Other & $\begin{array}{l}-0.005 \\
(0.71)\end{array}$ & $\begin{array}{c}0.063 \\
(8.17)^{* *}\end{array}$ & $\begin{array}{c}-0.044 \\
(4.46)^{* *}\end{array}$ & $\begin{array}{c}0.058 \\
(6.02)^{* *}\end{array}$ & $\begin{array}{c}0.182 \\
(19.02)^{* *}\end{array}$ \\
\hline $\begin{array}{l}\text { Gender (= } 1 \text { if } \\
\text { Female) }\end{array}$ & $\begin{array}{c}0.083 \\
(39.49)^{* *}\end{array}$ & $\begin{array}{c}-0.081 \\
(38.07)^{* *}\end{array}$ & $\begin{array}{c}-0.016 \\
(6.21)^{* *}\end{array}$ & $\begin{array}{c}0.007 \\
(2.93)^{* *}\end{array}$ & $\begin{array}{c}0.192 \\
(79.06)^{* *}\end{array}$ \\
\hline $\begin{array}{l}\text { Free school meal } \\
\text { status (= } 1 \text { if has } \\
\text { FSM) }\end{array}$ & $\begin{array}{c}-0.245 \\
(80.43)^{* *}\end{array}$ & $\begin{array}{c}-0.267 \\
(85.77)^{* *}\end{array}$ & $\begin{array}{c}-0.233 \\
(57.06)^{* *}\end{array}$ & $\begin{array}{c}-0.287 \\
(72.41)^{* *}\end{array}$ & $\begin{array}{c}-0.333 \\
(84.86)^{* *}\end{array}$ \\
\hline $\begin{array}{l}\text { SEN (= } 1 \text { if without } \\
\text { statement) }\end{array}$ & $\begin{array}{c}-1.107 \\
(431.27)^{* *}\end{array}$ & $\begin{array}{c}-1.082 \\
(412.32)^{* *}\end{array}$ & $\begin{array}{c}-0.912 \\
(247.11)^{* *}\end{array}$ & $\begin{array}{c}-0.937 \\
(262.02)^{* *}\end{array}$ & $\begin{array}{c}-0.915 \\
(258.46)^{* *}\end{array}$ \\
\hline $\begin{array}{l}\text { SEN status (= } 1 \text { if } \\
\text { with statement) }\end{array}$ & $\begin{array}{c}-1.825 \\
(260.93)^{* *}\end{array}$ & $\begin{array}{c}-1.815 \\
(253.81)^{* *}\end{array}$ & $\begin{array}{c}-1.576 \\
(182.82)^{* *}\end{array}$ & $\begin{array}{c}-1.434 \\
(171.57)^{* *}\end{array}$ & $\begin{array}{c}-1.211 \\
(146.31)^{* *}\end{array}$ \\
\hline $\mathbf{R}^{2}$ & 0.41 & 0.38 & 0.28 & 0.32 & 0.35 \\
\hline Observations & 554,412 & 554,412 & 461,461 & 461,461 & 461,461 \\
\hline & leses & & & \\
\hline $\begin{array}{ll}1 & \text { Also included } \\
2 & \text { and month of } \\
3 & \text { This refers to } 1 \\
4 & \text { This refers to } 1 \\
5 & \text { This refers to } 1 \\
\text { This refers to } 1\end{array}$ & $\begin{array}{l}\text { n the regressio } \\
\text { irth. } \\
\text { ey-stage } 1 . \\
\text { ey-stage } 2 . \\
\text { ey-stage } 3 . \\
\text { ey-stage } 4 .\end{array}$ & but not report & $d$ here were du & imies for mosa & classification \\
\hline
\end{tabular}




\section{Figure 5: 'Group'-White ethnicity conditional gaps ${ }^{1}$ in standardised values of overall key-stage scores through time for cohorts 1 and 2}
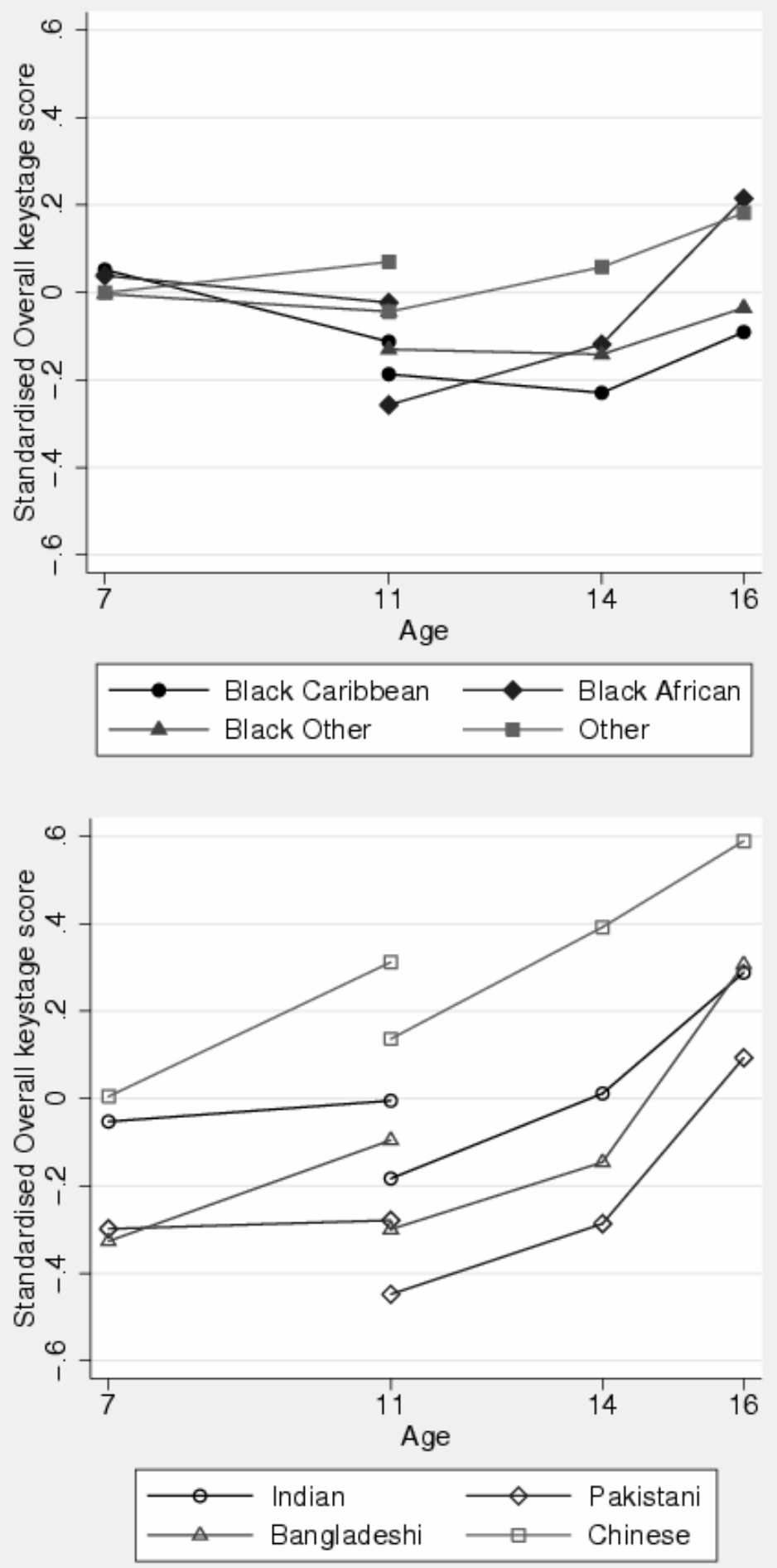

Notes:

1 These 'gaps' are the coefficients on the relevant ethnic group dummy of a regression of the standardised value of the specific overall key-stage test score on dummies for ethnic group (White pupils are the control group), Gender, FSM status, SEN status and Mosaic classification. 


\section{Value Added Gaps}

These results have analysed the data as a set of repeated cross-sections on the same pupils. We now cut the data the other way and take a longitudinal perspective, following each pupil in the two cohorts through the tests at different ages. We measure progress through the tests following the Department for Education and Skills approach to value added, as discussed above. Since value added involves analysing scores from just one test, there is no problem of comparing across different metrics and hence no need to standardise. Therefore, we use GCSE points as the metric. We regress these measures on the same independent variables as used above. Note again that the time-varying variables are only measured once, at the end of each cohort, in 2002. Thus while the data could be set up as a panel, none of the right hand side variables have any time variation.

In Table 7 we focus on value added from age 11 tests to the age 16 exams (KS2 to KS4), and consider the impact of adding different control variables. The omitted ethnic group is whites, so a positive coefficient on another ethnic group implies that that group experienced greater progress on average. Given the results above, we would expect ethnic minority groups to have higher value added than whites, and Table 7 shows this to be so. The coefficients are generally stable across the specifications, though less so for students with Black Caribbean or other Black heritage. This is rather different from the marked changes across the columns of the equivalent table for GCSE scores (table 5) as extra controls are added. This arises because value added measures progress, and these other controls appear to have a lesser impact on the change in test scores than they do on the score level at age 16 . Similarly, the $\mathrm{R}^{2}$ values are a lot lower, confirming that we can explain much less of change than level. Again note that ethnicity per se only explains $2 \%$ of variation in pupil progress. In fact, the ethnicity coefficients decline slightly as personal controls are added. This may be because the steep decline in the performance of poor white students (Figure 3) is partialled out in column 2, thus slightly raising the conditional relative performance of white pupils.

We adopt specification 4 of Table 7 and run this set of controls on all the value added measures; the results are in Table 8 , and we focus on the ethnicity coefficients. Note that the units for each column are the units of the ending test; so for example, in the final column, the units are KS4 (GCSE) points as it is value added between KS3 and KS4. In the secondary school cohort, all but two of the ethnicity coefficients are positive. These two are for value added KS2 (age 11) to KS3 (age 14) for students with Black Caribbean or other Black heritage. All minority groups on average progress better than white students taking secondary school as a whole, from age 11 to age 16, and all also make greater relative progress over the final two years of secondary schooling leading 
up to the most important exams. The size of the effect is not trivial. For students of Black African heritage, or with Bangladeshi, Pakistani, Indian or Chinese ethnicity, the difference in value-added is around 3 GCSE points. ${ }^{16}$ This is just over twice the size of the gender gap (at 1.43 points) and the impact of poverty on progress (1.27). The difference for students with Black Caribbean or other Black heritage at around 0.4 is lower, but still positive.

The primary school cohort tells a different story in terms of value added. While the relative progress is greater on average for students of Bangladeshi, Indian or Chinese ethnicity than white students, it is lower on average for students with Black heritage or Pakistani ethnicity. This difference could arise from three sources, and with just one secondary school cohort and primary school cohort it is impossible to say which is most likely. It could be something specific to the time period, or it could be something specific to either of these cohorts, or it could be some substantive difference in the way that secondary and primary schooling acts on students of different ethnicities. It is interesting to note that the gender gap is also reversed between the two cohorts.

\section{Attainment Gaps at Lower Quantiles}

So far, the analysis has been concerned solely with group mean performance. Given our universe data, we can look at the entire distribution, and in this section we focus on lower quantiles. Figures 6 and 7 repeat the unconditional normalised scores in Figure 1 but at the 25th percentile and 10th percentiles respectively. The pattern for the lower quartile is similar to that for the mean, though there are some interesting differences. In the secondary school cohort, we see students of Indian ethnicity overtaking white students by age 16, and ethnic Bangladeshi students catching up. Similarly, Black African students catch up relative to white students, while students with Black Caribbean or other Black heritage remain substantially below white scores. In the primary cohort, the most noteworthy factor is the steep decline in the relative performance of Black Caribbean students. ${ }^{17}$ Looking at the 10th percentiles in Figure 7, the discreteness of the scores in the early tests means that a lot of groups have the same scores. To the extent that there are differences, the previous pattern remains - ethnic minority groups overtaking or catching up white students.

16 This seems at odds with the comparison of the repeated cross-sections on the standardised z-scores. But they are very different metrics, so a direct comparison is misleading.

17 Note that the lines for Pakistani students in the primary cohort is the same as Bangladeshi students, and for whites in the primary cohort is the same as other Black students. 


\section{Figure 6: Raw values of standardised values of key-stage ${ }^{1}$ scores through time for cohorts 1 and 2 using the twenty-fifth percentile}
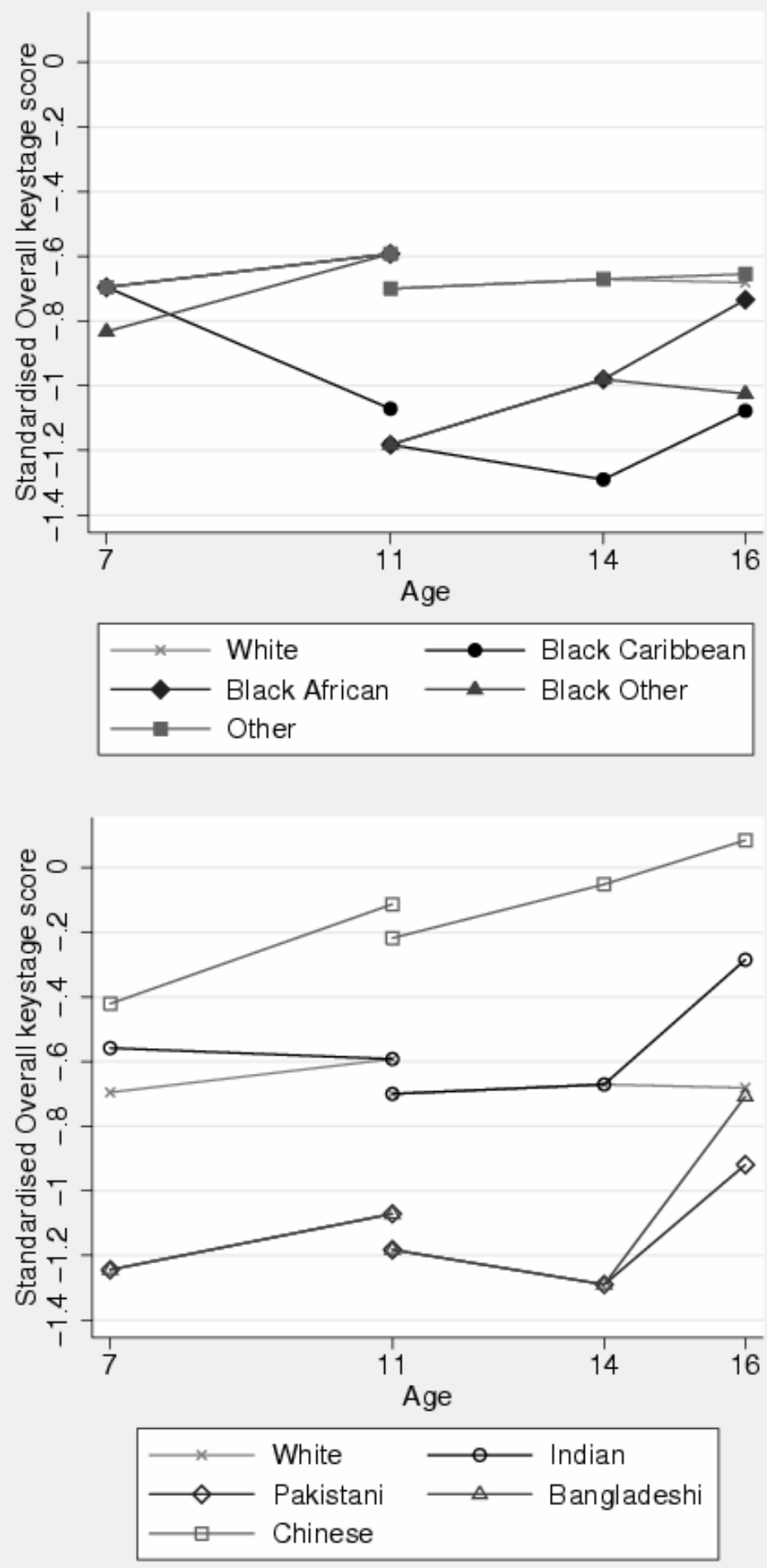

Notes:

1. Key-stage 1 assessment takes place at aged 7, key-stage 2 at aged 11, key-stage 3 at aged 14 and key-stage 4 at aged 16.

White and Black African pupils have the same value as Other pupils and Pakistani pupils have the same values as Bangladeshi pupils in cohort 1. 


\section{Figure 7: Raw values of standardised values of key-stage ${ }^{1}$ scores through time for cohorts 1 and 2 using the tenth percentile}
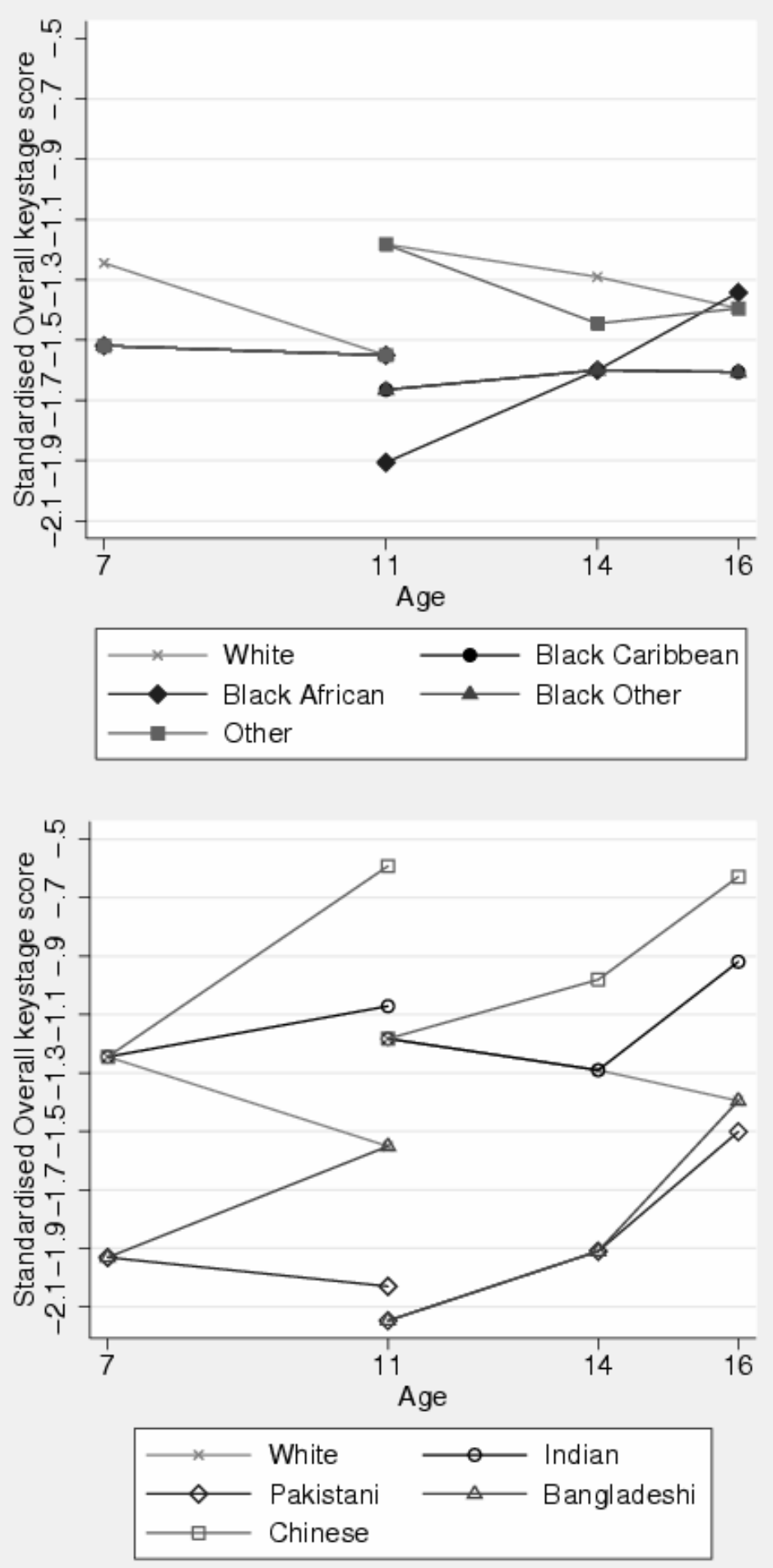

Notes:

1Key-stage 1 assessment takes place at aged 7, key-stage 2 at aged 11, key-stage 3 at aged 14 and key-stage 4 at aged 16.

Black African, Black Caribbean and Black Other pupils have the same value as Other pupils in cohort 1. In cohort 2, Black Caribbean pupils have the same value as Black Other pupils. 
Table 7: Regressions of key-stage 2 to 4 value added for cohort 2

\begin{tabular}{|c|c|c|c|c|c|}
\hline & "Explanatory Variables & 1 & 2 & 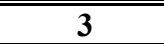 & 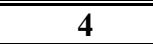 \\
\hline \multirow{16}{*}{ Ethnic Group } & \multirow{2}{*}{ Black African } & 1.961 & 2.767 & 3.234 & 2.971 \\
\hline & & $(24.40)^{* *}$ & $(35.82)^{* *}$ & $(41.67)^{* *}$ & $(37.35)^{* *}$ \\
\hline & \multirow{2}{*}{ Black Caribbean } & -0.701 & -0.026 & 0.489 & 0.372 \\
\hline & & $(11.14)^{* *}$ & $(0.43)$ & $(8.08)^{* *}$ & $(6.04)^{* *}$ \\
\hline & \multirow{2}{*}{ Black Other } & -0.493 & 0.107 & 0.486 & 0.434 \\
\hline & & $(5.91)^{* *}$ & $(1.34)$ & $(6.02)^{* *}$ & $(5.41)^{* *}$ \\
\hline & \multirow{2}{*}{ Bangladeshi } & 2.429 & 3.693 & 4.440 & 3.837 \\
\hline & & $(30.79)^{* *}$ & $(48.37)^{* *}$ & $(57.26)^{* *}$ & $(47.89)^{* *}$ \\
\hline & \multirow{2}{*}{ Indian } & 2.987 & 2.975 & 3.334 & 2.988 \\
\hline & & $(65.09)^{* *}$ & $(67.64)^{* *}$ & $(75.87)^{* *}$ & $(62.43)^{* *}$ \\
\hline & \multirow{2}{*}{ Pakistani } & 2.001 & 2.819 & 3.534 & 3.056 \\
\hline & & $(42.47)^{* *}$ & $(61.85)^{* *}$ & $(76.98)^{* *}$ & $(57.52)^{* *}$ \\
\hline & \multirow{2}{*}{ Chinese } & 3.249 & 3.196 & 3.310 & 3.205 \\
\hline & & $(25.38)^{* *}$ & $(26.02)^{* *}$ & $(26.89)^{* *}$ & $(26.58)^{* *}$ \\
\hline & \multirow{2}{*}{ Other } & 1.059 & 1.419 & 1.645 & 1.517 \\
\hline & & $(18.79)^{* *}$ & $(26.23)^{* *}$ & $(30.32)^{* *}$ & $(27.97)^{* *}$ \\
\hline \multirow{8}{*}{$\begin{array}{l}\text { Personal } \\
\text { Characteristics }\end{array}$} & Gender $(=1$ if Female) & No & $\begin{array}{c}1.381 \\
(98.23)^{* *}\end{array}$ & $\begin{array}{c}1.404 \\
(99.81)^{* * *}\end{array}$ & $\begin{array}{c}1.435 \\
(104.26)^{* *}\end{array}$ \\
\hline & Free School Meal Status $(=1$ if & \multirow{2}{*}{ No } & -2.278 & -1.721 & -1.273 \\
\hline & has FSM) & & $(111.64)^{* *}$ & $(77.57)^{* *}$ & $(57.05)^{* *}$ \\
\hline & SEN $(=1$ if SEN without & \multirow{2}{*}{ No } & -2.278 & -2.157 & -1.938 \\
\hline & statement) & & $(111.64)^{* *}$ & $(105.51)^{* *}$ & $(96.25)^{* *}$ \\
\hline & $\mathrm{SEN}(=1$ if SEN with & \multirow{2}{*}{ No } & -1.142 & -1.063 & -0.841 \\
\hline & statement) & & $(23.87)^{* *}$ & $(22.15)^{* *}$ & $(17.89)^{* *}$ \\
\hline & Month of Birth & No & Yes & Yes & Yes \\
\hline Neighbourhood & Index of Multiple Deprivation & No & No & Yes & No \\
\hline Characteristics & Mosaic Classification & No & No & No & Yes \\
\hline & & 0.02 & 0.10 & 0.12 & 0.14 \\
\hline Observations $^{2}$ & & 467,305 & 466,987 & 455,848 & 461,306 \\
\hline
\end{tabular}

Absolute values of t-statistics in parentheses

* Significant at $5 \% \quad * *$ Significant at $1 \%$

Notes:

1. Different numbers of observations for different specifications is due to missing data on some controls. 
Table 8: Regressions of value added measures ${ }^{1}$

\begin{tabular}{|c|c|c|c|c|}
\hline \multirow{2}{*}{$\begin{array}{l}\text { Explanatory } \\
\text { variable }\end{array}$} & \multicolumn{2}{|l|}{ Cohort 1} & \multicolumn{2}{|l|}{ Cohort 2} \\
\hline & $\begin{array}{l}\text { Key-stage 1-2 } \\
\text { Value added }\end{array}$ & $\begin{array}{c}\text { Key-stage } 2-4 \\
\text { Value added }\end{array}$ & $\begin{array}{l}\text { Key-stage 2-3 } \\
\text { Value added }\end{array}$ & $\begin{array}{l}\text { Key-stage 3-4 } \\
\text { Value added }\end{array}$ \\
\hline \multirow{2}{*}{ Black African } & -0.431 & 2.971 & 0.631 & 1.935 \\
\hline & $(5.53)^{* *}$ & $(37.35)^{* *}$ & $(10.59)^{* *}$ & $(34.72)^{* *}$ \\
\hline \multirow{2}{*}{$\begin{array}{l}\text { Black } \\
\text { Caribbean }\end{array}$} & -1.212 & 0.372 & -0.406 & 0.634 \\
\hline & $(18.51)^{* *}$ & $(6.04)^{* *}$ & $(8.81)^{* *}$ & $(14.71)^{* *}$ \\
\hline \multirow{2}{*}{ Black Other } & -0.322 & 0.434 & -0.170 & 0.524 \\
\hline & $(3.82)^{* *}$ & $(5.41)^{* *}$ & $(2.83)^{* *}$ & $(9.34)^{* *}$ \\
\hline \multirow{2}{*}{ Bangladeshi } & 1.139 & 3.837 & 0.687 & 2.676 \\
\hline & $(13.55)^{* *}$ & $(47.89)^{* *}$ & $(11.44)^{* *}$ & $(47.68)^{* *}$ \\
\hline \multirow{2}{*}{ Indian } & 0.324 & 2.988 & 1.103 & 1.741 \\
\hline & $(5.87)^{* *}$ & $(62.43)^{* *}$ & $(30.75)^{* *}$ & $(51.93)^{* *}$ \\
\hline \multirow{2}{*}{ Pakistani } & -0.507 & 3.056 & 0.617 & 2.080 \\
\hline & $(8.83)^{* *}$ & $(57.52)^{* *}$ & $(15.49)^{* *}$ & $(55.88)^{* *}$ \\
\hline \multirow{2}{*}{ Chinese } & 2.545 & 3.205 & 1.757 & 1.670 \\
\hline & $(18.25)^{* *}$ & $(26.58)^{* *}$ & $(19.44)^{* *}$ & $(19.76)^{* *}$ \\
\hline \multirow{2}{*}{ Other } & 0.490 & 1.517 & 0.609 & 0.834 \\
\hline & $(9.19)^{* *}$ & $(27.97)^{* *}$ & $(14.99)^{* *}$ & $(21.96)^{* *}$ \\
\hline \multirow{2}{*}{$\begin{array}{l}\text { Gender (= } 1 \text { if } \\
\text { female) }\end{array}$} & -1.225 & 1.435 & 0.117 & 1.162 \\
\hline & $(82.79)^{* *}$ & $(104.26)^{* *}$ & $(11.31)^{* *}$ & $(120.54)^{* *}$ \\
\hline \multirow{2}{*}{$\begin{array}{l}\text { Free school } \\
\text { meal status }(=1 \\
\text { if has FSM) }\end{array}$} & -0.711 & -1.273 & -0.552 & -0.567 \\
\hline & $(32.98)^{* *}$ & $(57.05)^{* *}$ & $(32.99)^{* *}$ & $(36.27)^{* *}$ \\
\hline \multirow{2}{*}{$\begin{array}{l}\text { SEN status (= } 1 \\
\text { if without } \\
\text { statement) }\end{array}$} & -2.280 & -1.938 & -0.968 & -0.754 \\
\hline & $(125.58)^{* *}$ & $(96.25)^{* *}$ & $(64.18)^{* *}$ & $(53.46)^{* *}$ \\
\hline \multirow{2}{*}{$\begin{array}{l}\text { SEN status (= } 1 \\
\text { if with } \\
\text { statement) }\end{array}$} & -4.643 & -0.841 & -0.897 & -0.128 \\
\hline & $(93.84)^{* *}$ & $(17.89)^{* *}$ & $(25.45)^{* *}$ & $(3.90)^{* *}$ \\
\hline $\mathbf{R}^{2}$ & 0.08 & 0.14 & 0.06 & 0.09 \\
\hline Observations & 554,382 & 461,306 & 461,306 & 461,306 \\
\hline \multicolumn{5}{|c|}{$\begin{array}{l}\text { Absolute values of t-statistics in parentheses } \\
* \text { Significant at } 5 \% \quad * * \text { Significant at } 1 \%\end{array}$} \\
\hline \multicolumn{5}{|l|}{ Notes: } \\
\hline $\begin{array}{l}\text { Also inclu } \\
\text { and month }\end{array}$ & the regressior & not reported $\mathrm{h}$ & re dummies & saic classif \\
\hline
\end{tabular}


We confirm this visual impression and address issues of statistical significance using quantile regression at the 25th percentile. Only KS4 scores are sufficiently continuous enough to make quantile regression sensible. The results in Table 9 show the same pattern as we have seen above, with the same groups doing well at the bottom of the distribution as do well at the mean.

\section{Table 9: Quantile regressions (25th percentile) of standardised values of overall key-stage score ${ }^{1}$}

\begin{tabular}{lc}
\hline Explanatory variable & Cohort $\mathbf{2}$ \\
Age 16 \\
\hline Black African & 0.248 \\
Black Caribbean & $(15.03)^{* *}$ \\
Black Other & -0.053 \\
& $(4.16)^{* *}$ \\
Bangladeshi & -0.041 \\
& $(2.46)^{*}$ \\
Indian & 0.309 \\
Pakistani & $(18.65)^{* *}$ \\
Chinese & 0.293 \\
Other & $(29.65)^{* *}$ \\
& 0.098 \\
Gender (= 1 if Female) & $(8.88)^{* *}$ \\
Free school meal status (= 1 if has FSM) & 0.563 \\
SEN (= 1 if without statement) & $(22.62)^{* *}$ \\
SEN status (= 1 if with statement) & 0.132 \\
Obeudo R & $(11.78)^{* *}$ \\
\hline \hline & 0.201 \\
& $(70.72)^{* *}$ \\
& -0.340 \\
& $(72.00)^{* *}$ \\
& -0.923 \\
& $(219.16)^{* *}$ \\
& -1.175 \\
& $(120.55)^{* *}$ \\
& 0.22 \\
& 461,461 \\
\hline
\end{tabular}

Absolute values of t-statistics in parentheses

* Significant at 5\% * Significant at $1 \%$

Notes:

1. Also included in the regressions but not reported here were dummies for mosaic classification.

2. This refers to key-stage 4 . 


\section{Quantifying the gap}

Finally in this section, we characterise the change over the period of secondary schooling in terms of the impact on the gateway standard to post-compulsory schooling - acquiring 5 or more $\mathrm{A}$ to $\mathrm{C}$ grade passes in the age 16 exams (GCSEs). These numbers illustrate the quantitative significance of the differential progress of these groups through secondary school. These calculations refer to the unconditional progress; using the conditional data would produce even stronger effects. Using the sample of white students in cohort 2, we estimate the probability of such an attainment level as a function of the age 11 test score (and gender). We then use this to predict the likelihood of 5 A-C grades for ethnic minority students, and compare this with the outcome. The difference is one measure of the extent of the change in relative performance during secondary school.

Table 10: Predicted vs actual GCSE attainment by ethnicity

\begin{tabular}{lcc}
\hline \hline Ethnicity & $\begin{array}{c}\text { Actual percentage of } \\
\text { pupils obtaining 5 or } \\
\text { more A-Cs at GCSE }\end{array}$ & $\begin{array}{c}\text { Predicted percentage of } \\
\text { pupils obtaining 5 or } \\
\text { more A-Cs at GCSE }\end{array}$ \\
\hline Black African & $48.24 \%$ & $39.22 \%$ \\
Black Caribbean & $32.55 \%$ & $38.76 \%$ \\
Black Other & $38.06 \%$ & $41.91 \%$ \\
Bangladeshi & $47.98 \%$ & $35.67 \%$ \\
Indian & $64.97 \%$ & $47.98 \%$ \\
Pakistani & $41.57 \%$ & $32.30 \%$ \\
Chinese & $76.25 \%$ & $58.76 \%$ \\
Other & $53.93 \%$ & $49.28 \%$ \\
White & $52.68 \%$ & $52.68 \%$ \\
\hline \hline
\end{tabular}

Notes:

1. Percentage of pupils attainment 5 or more A-Cs at GCSE is predicted by running a logit of whether pupil attains 5 or more A-Cs on overall Key-stage 2 score and gender for White pupils only.

The results are in Table 10. They show that the relative progress shown by minority ethnic groups during secondary schooling translates into substantial differences in predicted GCSE passes. Taking students with Black African heritage, if they had remained in the same position in the test score distribution throughout secondary schooling, then as a group, 39\% would have achieved at least 5 passes in the high-stakes age 16 exams. In fact, 48\% achieved that level, a difference of nearly one quarter. For ethnic Bangladeshi students, the actual figure of $48 \%$ is a third higher than the predicted figure of $36 \%$. Similarly, for ethnic Indian, Pakistani and Chinese students. The situation is reversed for 
students with Black Caribbean or other Black heritage, though from Figure 1, we would have expected little difference between the two figures. This is due to a different distribution of total GCSE points around the score required for five passes.

\section{Results II: Possible Explanations}

Before addressing the potential substantive explanations set out above, we deal with a straightforward statistical factor. It could be that individuals starting out below average in the early tests show progress simply due to mean reversion: they were unlucky or under-performed in one test and return to normal in the later tests. If some ethnic minorities are dis-proportionately in the low-scoring groups early on, the mean reversion will show up as dis-proportionate progress. This seems unlikely in that for some groups, the picture is not convergence to the mean, but catch-up and over-taking. But one straightforward way to test this is to use simple matching techniques. For each pupil in each ethnic minority group, we select a white pupil matched on gender, poverty status and KS2 score. ${ }^{18}$ We then compare the progress of this matched group of pupils with the minority pupils. The results are in Figure 8, and show that the substantially differential progress noted so far is reflecting a real phenomenon.

We categorise the potential substantive explanations using the schema set out above: non-school factors, systemic school issues, between-school factors and within-school factors.

18 There are obviously very many such white pupils per minority pupil: we randomly select one. We then repeat this whole process ten times and the results presented in Figure 8 are the average over all these runs. 
Figure 8: Performance of equivalent 'Group'-White pupils in cohort 2 based on FSM status, gender and KS2 mean score
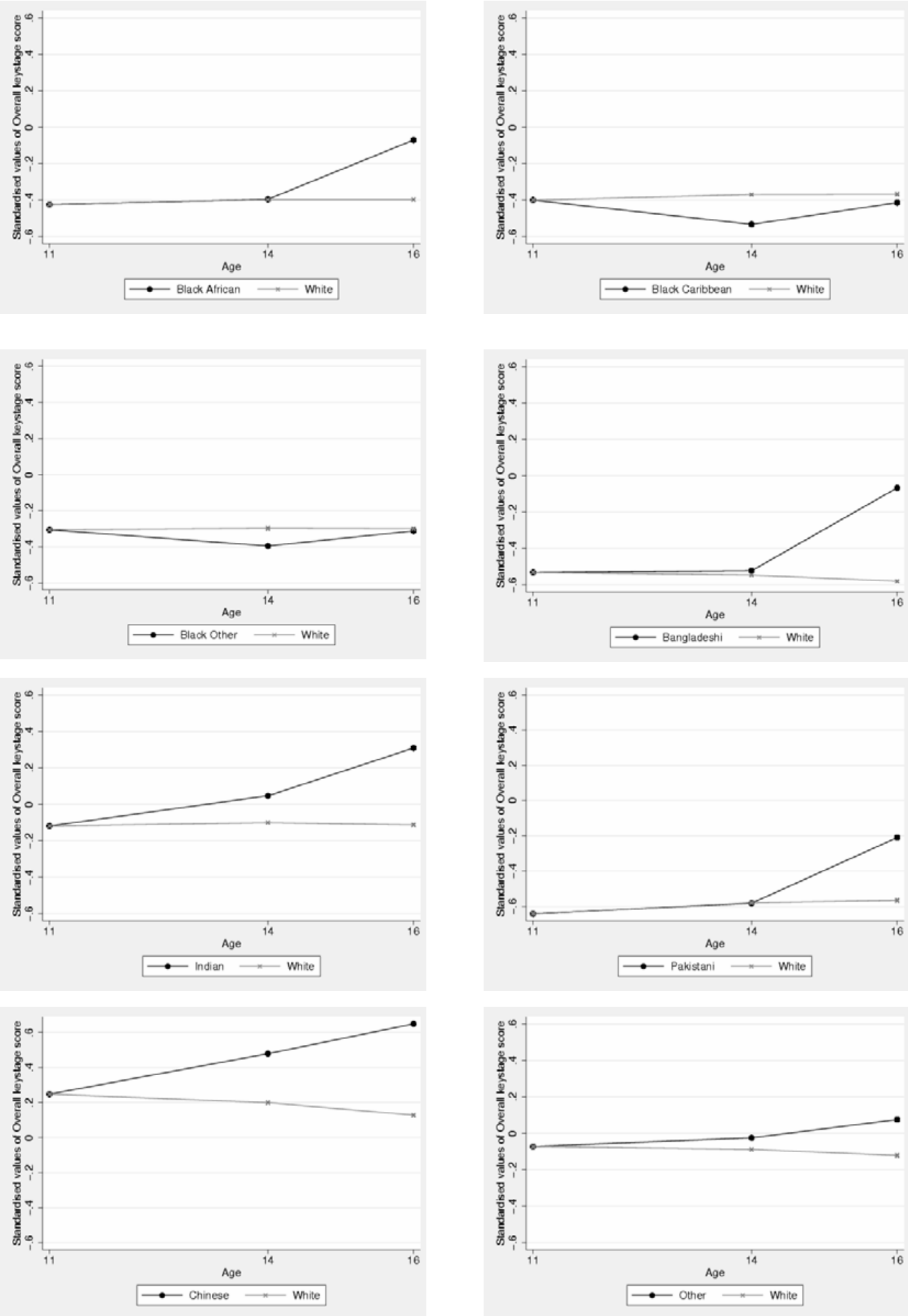
Table 11: Regressions of standardised values of cohort 2 KS4 score $^{1}$

\begin{tabular}{|c|c|c|c|c|c|c|c|c|c|c|c|c|c|c|}
\hline \multirow[b]{2}{*}{ Ethnicity } & \multirow[b]{2}{*}{ None $^{2}$} & \multirow[b]{2}{*}{$\begin{array}{c}\text { FSM } \\
\text { status }\end{array}$} & \multirow[b]{2}{*}{ Gender } & \multicolumn{6}{|c|}{ Interactions } & \multirow[b]{2}{*}{ Grammar } & \multirow[b]{2}{*}{$\begin{array}{c}\text { School } \\
\text { value } \\
\text { added }\end{array}$} & \multirow[b]{2}{*}{$\begin{array}{c}\text { School } \\
\text { value } \\
\text { added } \\
\text { squared }\end{array}$} & \multirow[b]{2}{*}{$\mathbf{R}^{2}$} & \multirow[b]{2}{*}{ Obs } \\
\hline & & & & $\begin{array}{l}\text { School } \\
\text { FSM }^{3}\end{array}$ & $\begin{array}{c}\text { Propn of } \\
\text { girls }^{4}\end{array}$ & $\begin{array}{l}\text { Own } \\
\text { FSM * } \\
\text { School } \\
\text { FSM }^{5}\end{array}$ & $\begin{array}{l}\text { School } \\
\text { size }\end{array}$ & $\begin{array}{c}\text { School } \\
\text { size } \\
\text { squared }\end{array}$ & $\begin{array}{l}\text { Secondary } \\
\text { modern }\end{array}$ & & & & & \\
\hline $\begin{array}{l}\text { Black } \\
\text { African }\end{array}$ & $\begin{array}{l}0.188 \\
(1.47)\end{array}$ & $\begin{array}{l}0.102 \\
(1.76)\end{array}$ & $\begin{array}{l}0.052 \\
(1.59)\end{array}$ & $\begin{array}{l}-0.289 \\
(2.44)^{*}\end{array}$ & $\begin{array}{l}0.064 \\
(1.14)\end{array}$ & $\begin{array}{l}0.086 \\
(0.50)\end{array}$ & $\begin{array}{l}-0.004 \\
(0.21)\end{array}$ & $\begin{array}{l}0.000 \\
(0.12)\end{array}$ & $\begin{array}{l}-0.032 \\
(0.31)\end{array}$ & $\begin{array}{c}0.239 \\
(1.97)^{*}\end{array}$ & $\begin{array}{l}-0.017 \\
(2.05)^{*}\end{array}$ & $\begin{array}{r}-0.001 \\
(0.36)\end{array}$ & 0.41 & 415,274 \\
\hline $\begin{array}{l}\text { Black } \\
\text { Caribbean }\end{array}$ & $\begin{array}{l}-0.033 \\
(0.41)\end{array}$ & $\begin{array}{c}0.234 \\
(4.94)^{* *}\end{array}$ & $\begin{array}{c}0.054 \\
(2.36)^{*}\end{array}$ & $\begin{array}{l}-0.151 \\
(1.73)\end{array}$ & $\begin{array}{l}0.068 \\
(1.43)\end{array}$ & $\begin{array}{l}0.060 \\
(0.43)\end{array}$ & $\begin{array}{l}-0.030 \\
(2.48)^{*}\end{array}$ & $\begin{array}{c}0.001 \\
(2.62)^{* *}\end{array}$ & $\begin{array}{l}0.178 \\
(1.95)\end{array}$ & $\begin{array}{c}0.173 \\
(2.34)^{*}\end{array}$ & $\begin{array}{l}-0.013 \\
(1.89)\end{array}$ & $\begin{array}{l}-0.000 \\
(0.06)\end{array}$ & 0.41 & 417,731 \\
\hline Black Other & $\begin{array}{l}-0.259 \\
(2.07)^{*}\end{array}$ & $\begin{array}{c}0.169 \\
(2.81)^{* *}\end{array}$ & $\begin{array}{l}0.040 \\
(1.33)\end{array}$ & $\begin{array}{l}0.044 \\
(0.37)\end{array}$ & $\begin{array}{l}0.052 \\
(0.81)\end{array}$ & $\begin{array}{l}-0.159 \\
(0.85)\end{array}$ & $\begin{array}{l}0.025 \\
(1.20)\end{array}$ & $\begin{array}{l}-0.001 \\
(0.97)\end{array}$ & $\begin{array}{l}0.135 \\
(1.16)\end{array}$ & $\begin{array}{l}0.120 \\
(1.29)\end{array}$ & $\begin{array}{l}-0.010 \\
(1.08)\end{array}$ & $\begin{array}{l}-0.006 \\
(2.42)^{*}\end{array}$ & 0.41 & 414,987 \\
\hline Bangladeshi & $\begin{array}{l}0.233 \\
(1.73)\end{array}$ & $\begin{array}{c}0.219 \\
(3.98)^{* *}\end{array}$ & $\begin{array}{l}0.047 \\
(1.57)\end{array}$ & $\begin{array}{l}-0.077 \\
(0.78)\end{array}$ & $\begin{array}{l}0.101 \\
(1.75)\end{array}$ & $\begin{array}{l}0.047 \\
(0.37)\end{array}$ & $\begin{array}{l}-0.014 \\
(0.60)\end{array}$ & $\begin{array}{l}0.000 \\
(0.04)\end{array}$ & $\begin{array}{l}0.083 \\
(0.64)\end{array}$ & $\begin{array}{l}0.078 \\
(0.56)\end{array}$ & $\begin{array}{c}-0.043 \\
(5.77)^{* *}\end{array}$ & $\begin{array}{l}-0.02 \\
(0.63)\end{array}$ & 0.41 & 415,350 \\
\hline Indian & $\begin{array}{c}0.174 \\
(2.38)^{*}\end{array}$ & $\begin{array}{c}0.193 \\
(4.29)^{* *}\end{array}$ & $\begin{array}{l}0.016 \\
(1.00)\end{array}$ & $\begin{array}{l}-0.033 \\
(0.48)\end{array}$ & $\begin{array}{c}0.114 \\
(3.03)^{* *}\end{array}$ & $\begin{array}{l}-0.227 \\
(1.53)\end{array}$ & $\begin{array}{l}-0.005 \\
(0.47)\end{array}$ & $\begin{array}{l}0.000 \\
(0.54)\end{array}$ & $\begin{array}{l}0.024 \\
(0.71)\end{array}$ & $\begin{array}{c}-0.162 \\
(3.70)^{* *}\end{array}$ & $\begin{array}{c}-0.036 \\
(7.98)^{* *}\end{array}$ & $\begin{array}{l}-0.002 \\
(0.92)\end{array}$ & 0.41 & 423,479 \\
\hline Pakistani & $\begin{array}{l}-0.162 \\
(2.44)\end{array}$ & $\begin{array}{l}0.280 \\
(8.49)\end{array}$ & $\begin{array}{l}0.012 \\
(0.73)\end{array}$ & $\begin{array}{l}-0.118 \\
(1.90)\end{array}$ & $\begin{array}{l}0.171 \\
(4.45)\end{array}$ & $\begin{array}{l}-0.228 \\
(2.52)\end{array}$ & $\begin{array}{c}0.024 \\
(2.25)^{*}\end{array}$ & $\begin{array}{c}-0.001 \\
(2.89)^{* *}\end{array}$ & $\begin{array}{l}0.117 \\
(2.15)\end{array}$ & $\begin{array}{l}-0.038 \\
(1.04)\end{array}$ & $\begin{array}{l}-0.031 \\
(7.22)\end{array}$ & $\begin{array}{l}-0.001 \\
(0.36)\end{array}$ & 0.41 & 422,869 \\
\hline Chinese & $\begin{array}{l}0.360 \\
(1.90)\end{array}$ & $\begin{array}{c}0.574 \\
(4.84)^{* *}\end{array}$ & $\begin{array}{l}0.002 \\
(0.05)\end{array}$ & $\begin{array}{l}0.339 \\
(1.79)\end{array}$ & $\begin{array}{l}0.051 \\
(0.52)\end{array}$ & $\begin{array}{c}-0.673 \\
(1.98)^{*}\end{array}$ & $\begin{array}{l}0.002 \\
(0.07)\end{array}$ & $\begin{array}{l}-0.000 \\
(0.03)\end{array}$ & $\begin{array}{l}-0.133 \\
(1.71)\end{array}$ & $\begin{array}{l}-0.125 \\
(1.01)\end{array}$ & $\begin{array}{l}-0.015 \\
(1.10)\end{array}$ & $\begin{array}{l}-0.006 \\
(1.65)\end{array}$ & 0.41 & 412,994 \\
\hline Other & $\begin{array}{l}0.042 \\
(0.54)\end{array}$ & $\begin{array}{l}0.170 \\
(4.25) \\
\end{array}$ & $\begin{array}{l}0.003 \\
(0.12)\end{array}$ & $\begin{array}{l}-0.107 \\
(1.31)\end{array}$ & $\begin{array}{l}0.049 \\
(1.17)\end{array}$ & $\begin{array}{r}-0.064 \\
(0.49) \\
\end{array}$ & $\begin{array}{l}0.012 \\
(0.95)\end{array}$ & $\begin{array}{l}-0.001 \\
(1.12)\end{array}$ & $\begin{array}{l}-0.016 \\
(0.35)\end{array}$ & $\begin{array}{l}-0.051 \\
(1.04)\end{array}$ & $\begin{array}{l}0.007 \\
(1.28)\end{array}$ & $\begin{array}{l}-0.004 \\
(1.92)\end{array}$ & 0.41 & 419,298 \\
\hline
\end{tabular}

Absolute values of t-statistics in parentheses

* Significant at 5\% ** Significant at $1 \%$

Notes:

1. Each row represents a separate regression including pupils of particular ethnic group and White pupils.

2, Reported result is that from coefficient on the relevant ethnic group dummy without any interaction term.

3, School FSM is proportion of pupils within school who have FSM status.

4. Variable refers to proportion of girls in school.

5. Variable is interaction of pupil's own ethnicity with pupil's own FSM status multiplied by the proportion of pupils within the school who have FSM status. 
Table 12: Regressions of key-stage 2 to 4 value added for cohort 2

\begin{tabular}{|c|c|c|c|c|}
\hline & Explanatory Variables & 1 & 2 & 3 \\
\hline \multirow{2}{*}{ Ethnic Group } & \multirow{2}{*}{ Black African } & -0.568 & -0.410 & -0.356 \\
\hline & & $(6.21)^{* *}$ & $(4.42)^{* *}$ & $(3.23)^{* *}$ \\
\hline \multirow{11}{*}{$\begin{array}{l}\text { Personal } \\
\text { Characteristics }\end{array}$} & \multirow{2}{*}{$\begin{array}{l}\text { ESL ( }=1 \text { if English is not } \\
\text { mother tongue) }\end{array}$} & 0.744 & 0.875 & 0.901 \\
\hline & & $(8.37)^{* *}$ & $(9.71)^{* *}$ & $(9.90)^{* *}$ \\
\hline & \multirow{2}{*}{ Gender (= 1 if Female) } & 1.540 & 1.553 & 1.558 \\
\hline & & $(21.51)^{* *}$ & $(21.63)^{* *}$ & $(21.73)^{* *}$ \\
\hline & \multirow{2}{*}{$\begin{array}{l}\text { Free School Meal Status (= } 1 \\
\text { if has FSM) }\end{array}$} & -0.509 & -0.350 & -0.265 \\
\hline & & $(5.30)^{* *}$ & $(3.57)^{* *}$ & $(2.67)^{* *}$ \\
\hline & \multirow{2}{*}{$\begin{array}{l}\text { SEN (=1 if SEN without } \\
\text { statement) }\end{array}$} & -1.350 & -1.326 & -1.283 \\
\hline & & $(12.77)^{* *}$ & $(12.49)^{* *}$ & $(12.06)^{* *}$ \\
\hline & \multirow{2}{*}{$\begin{array}{l}\text { SEN (=1 if SEN with } \\
\text { statement) }\end{array}$} & -1.444 & -1.484 & -1.443 \\
\hline & & $(4.88)^{* *}$ & $(5.02)^{* *}$ & $(4.87)^{* *}$ \\
\hline & Month of Birth & Yes & Yes & Yes \\
\hline \multirow{2}{*}{$\begin{array}{l}\text { Neighbourhood } \\
\text { Characteristics }\end{array}$} & Index of Multiple Deprivation & No & Yes & No \\
\hline & Mosaic Classification & No & No & Yes \\
\hline $\mathrm{R}^{2}$ & & 0.06 & 0.07 & 0.08 \\
\hline Observations $^{1}$ & & 15,967 & 15,681 & 15,744 \\
\hline
\end{tabular}

Absolute values of t-statistics in parentheses

* Significant at $5 \% \quad * *$ Significant at $1 \%$

Notes:

1. Different numbers of observations for different specifications is due to missing data on some controls. 


\section{Non-school Factors}

In Table 11 we investigate whether the relative progress recorded by different ethnic minority groups depends on any individual characteristics. We re-run the KS4 regressions, interacting ethnicity with a range of characteristics. ${ }^{19}$ The only strong common factor across all groups is that progress is stronger among poor minority students than non-poor minority students. In the same table, though belonging in the between-schools section, we show that school gender mix matters for ethnic South Asian students, with higher fractions of girls raising performance; Black students in grammar schools also tend to progress faster.

One factor of potential importance is language. It seems likely that students whose first language is not English will find school difficult initially, and then improve. The progress that we have observed through school could be due to the simple passage of time in an environment where English is used intensively. We have some data to address this. PLASC records whether English is a pupil's "mother tongue", ${ }^{20}$ the language spoken at home. Unfortunately for the analysis, for many of the ethnic groups, there is little variation in this variable. For example: among Black Caribbean students, $7 \%$ do not have English as mother tongue; among students of Pakistani ethnicity, $93 \%$ do not, and among ethnic Bangladeshi students the figure is $97 \%$. Two groups where there is some variation are students with Black African heritage $(66 \%$ with a different language as mother tongue) and ethnic Indian students (85\%). We examine the role of language among these two groups, by repeating the value-added regressions from Table 7 just on these groups. We do not include white students as essentially all of them have English as mother tongue; consequently the coefficient for Black African ethnicity is to interpreted relative to the omitted group of ethnic Indian students. The results are in Table 12. The effect of having a different mother tongue than English is positive and significant. The size of the coefficient is interesting. It suggests that for these groups, having English as an additional language yields on average around 0.9 GCSE extra points. But Table 7 showed that both these groups gained 3 GCSE points relative to whites. Putting the two together suggests that differences in language may account for about a third of the gain of these ethnic minorities.

We also examine separately progress in English, Maths and Science. This is of independent interest as it does not aggregate over subjects, but it may also have some bearing on the language issue. Whilst in all three subjects the instruction

19 These are run slightly differently in that we run a separate regression for each group, based on that group plus white students, interacting the group dummy with the list of variables shown.

20 Note that this is a non-time varying variable - increasing fluency in English will not change what is identified as a pupil's mother tongue. 
will be in English, the actual work carried out by the student involves less English language use in maths than English. If so, and if this assumption is correct, we would expect to see an initial higher level in maths and faster progress in English for minority students whose mother tongue is not English. We repeat the regression analysis of Table 6 separately by these three subjects to produce conditional ethnicity coefficients, presented in Figure 9. Comparing Black African heritage students with other Black students in English and maths in cohort 2, we see a simliar pattern: the former score lower at age 11 tests, but overtake and score more highly by the age 16 tests. Similarly, the patterns among the ethnic South Asian students does not vary much between maths and English. 


\section{Figure 9a: 'Group'-White ethnicity conditional gaps ${ }^{1}$ in standardised}

values of English key-stage scores through time for cohorts 1 and 2
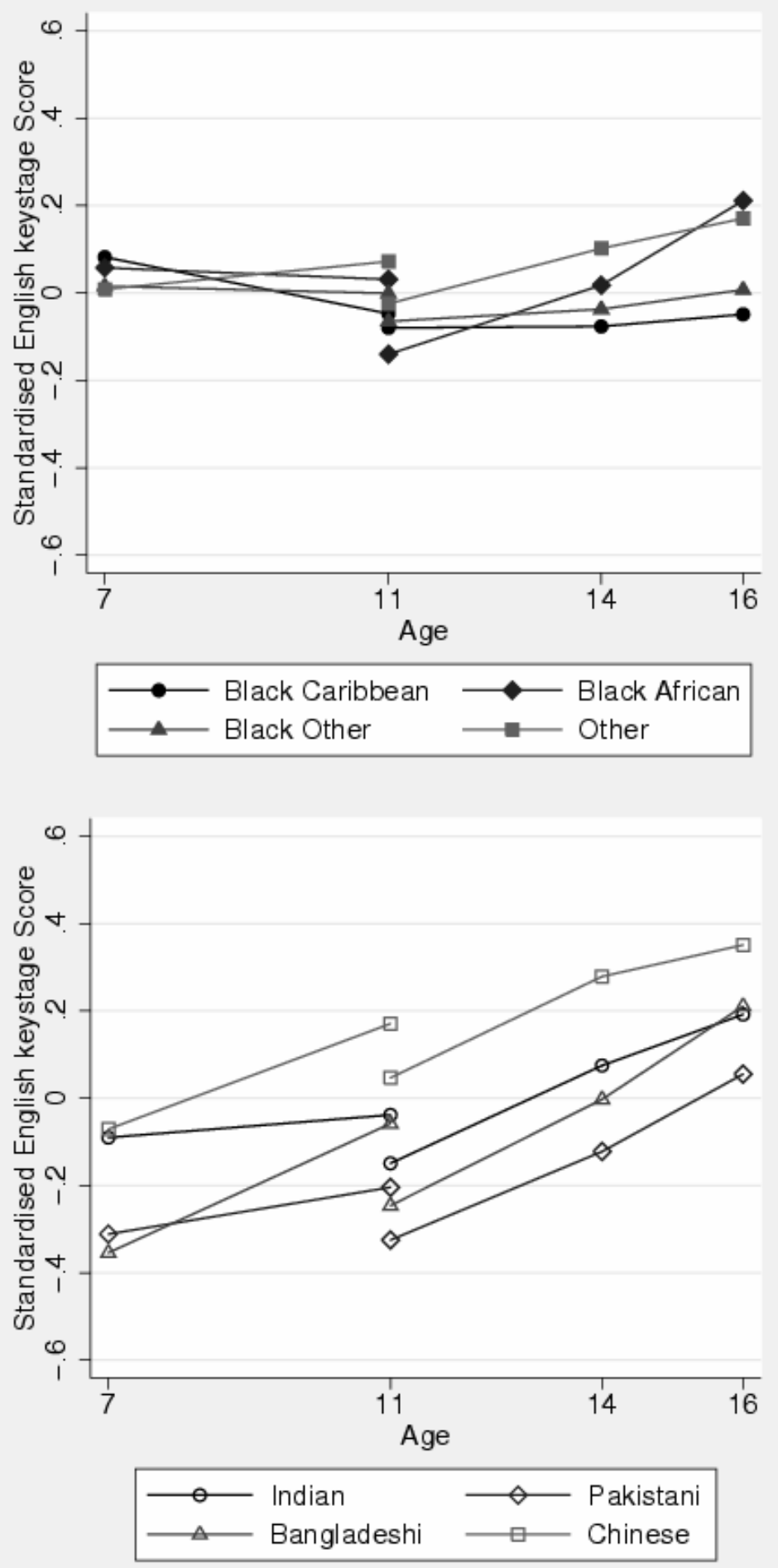

Notes:

1. These 'gaps' are the coefficients on the relevant ethnic group dummy of a regression of the standardised value of the specific overall key-stage test score on dummies for ethnic group (White pupils are the control group), Gender, FSM status, SEN status and Mosaic classification. 


\section{Figure 9b: 'Group'-White ethnicity conditional gaps ${ }^{1}$ in standardised}

values of maths key-stage scores through time for cohorts 1 and 2
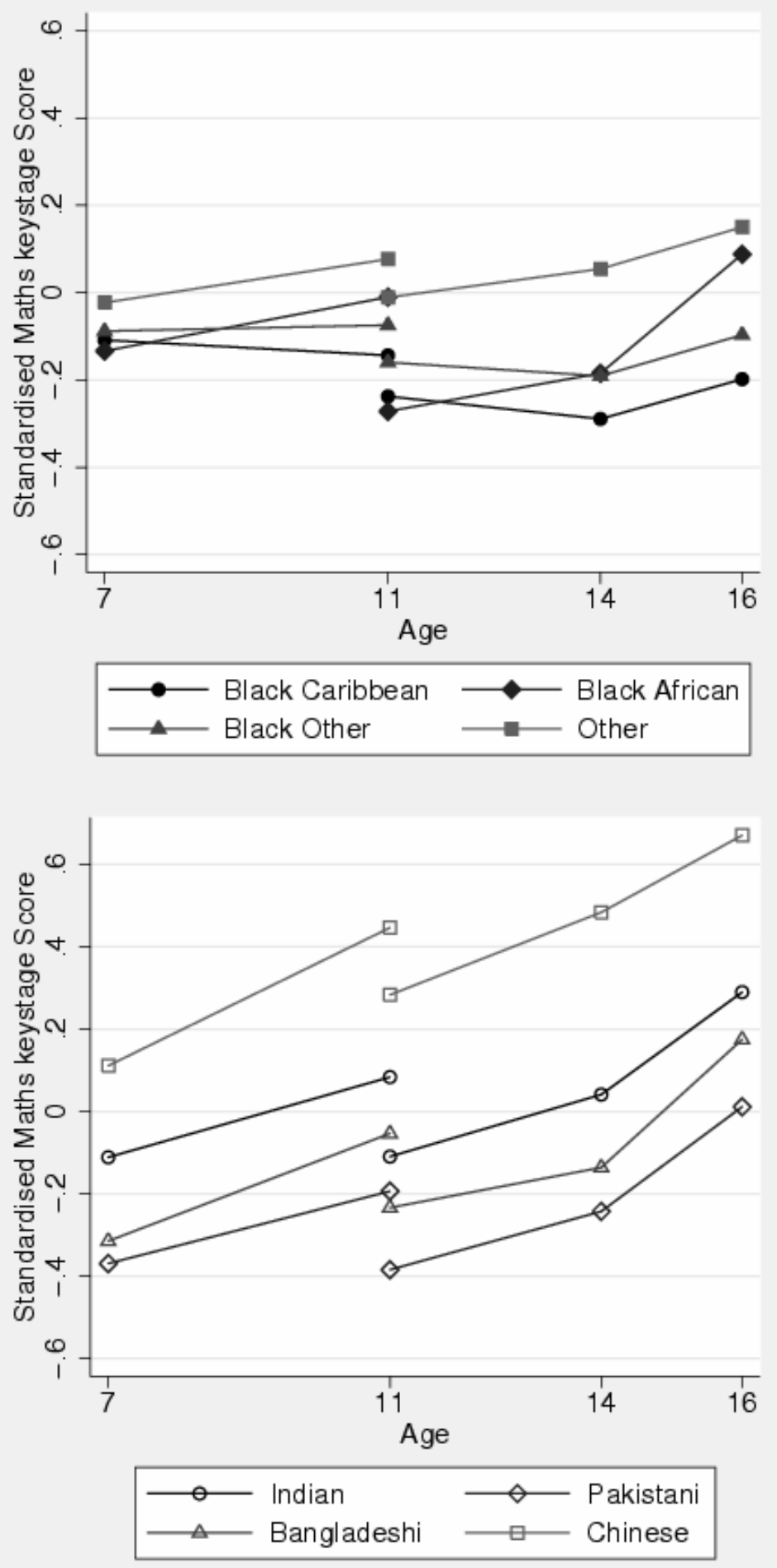

Notes:

1. These 'gaps' are the coefficients on the relevant ethnic group dummy of a regression of the standardised value of the specific overall key-stage test score on dummies for ethnic group (White pupils are the control group), Gender, FSM status, SEN status and Mosaic classification. 


\section{Figure 9c: 'Group'-White ethnicity conditional gaps ${ }^{1}$ in standardised values of science key-stage scores through time for cohorts 1 and 2}
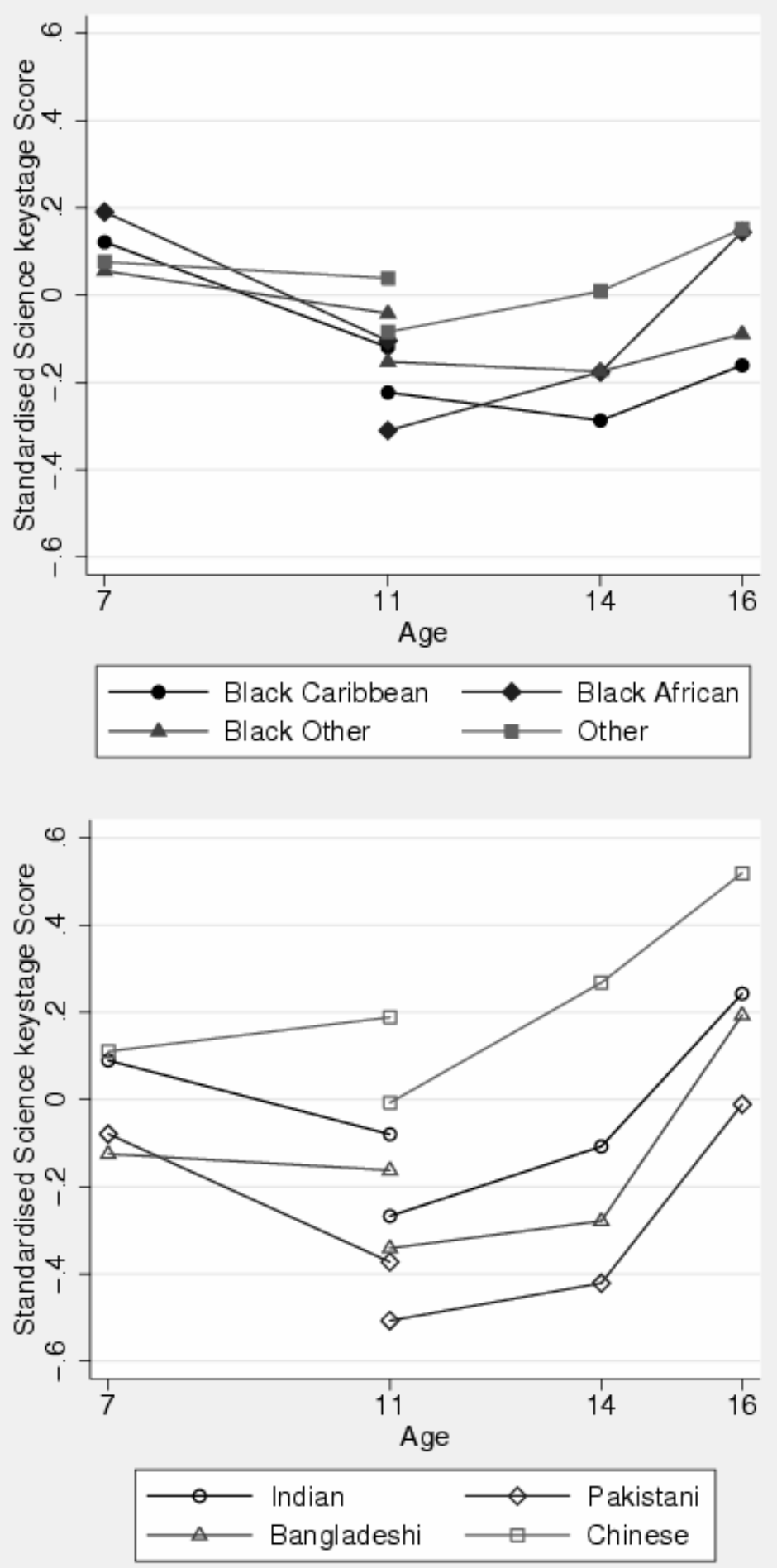

Notes:

1. These 'gaps' are the coefficients on the relevant ethnic group dummy of a regression of the standardised value of the specific overall key-stage test score on dummies for ethnic group (White pupils are the control group), Gender, FSM status, SEN status and Mosaic classification. 


\section{Systemic schooling factors}

A potential explanation for the improvement shown is changes in the marking and assessment procedures. For example, if the age 11 and age 14 tests were marked by students' own teachers, these might be influenced by teacher bias, or low teacher expectations of some ethnic minority pupils. ${ }^{21}$ Thus the apparent gain in performance would be simply the removal of that bias in the rigorously marked age 16 GCSEs. In fact, the marking procedures are very similar at these key-stages. At key-stages 2, 3 and 4 (GCSE) test scripts are all marked outside of the school, not by the student's own teacher. They are anonymous in the sense that the pupils are unknown to the marker, but not anonymous in that the pupil's name is on the test. The important fact is that the principles of assessment are essentially the same at age 11,14 and 16, though the system is much more complex at age 16 because of the much greater number of tests taken.

While this shows that teacher bias or expectations have no direct impact on the marking of test scores, they may be important in the teaching and learning process itself. We can explore this a little using this dataset. At KS2 and KS3, teacher assessments are recorded for pupils alongside the test scores. These are essentially the teacher's prediction of the test score, told to the students sometime in the year before the tests are taken. They are in exactly the same metric so are easily compared. We simply regress the test score against the teacher assessment, ethnicity dummies, and the interaction of the two. The results are in Table 13. Perhaps unsurprisingly, the teacher assessments are generally below the test scores as teachers do not want to encourage complacency. On top of that, however, there is evidence of greater divergences between test performance and teacher expectation for some ethnic groups. This occurs in some tests for most minority groups. For example, comparing a white student and a student of Black Caribbean heritage at KS2 English, if they had both scored 8 in the test, the latter would have been given an assessment 0.35 points lower, not a trivial difference. The lower assessment by teachers relative to subsequent test scores for some ethnic minority groups shown here is part of the general educational environment in which the test scores we report on here are achieved.

The role of the Special Educational Needs (SEN) dummies in the analysis needs to be briefly discussed. It is sometimes argued that Black Caribbean students are disproportionately labelled as having SEN, potentially impeding their progress. By conditioning on SEN we may be partialling out some of the effect of that 
ethnicity. ${ }^{22}$ To test this, we run the regressions underlying tables 6 and 8 without the SEN dummies. This changes the results for the attainment levels for pupils of Black Caribbean heritage from -0.091 in Table 6, column 5, to -0.141 , and for pupils of other Black heritage from -0.035 to -0.055 . Conversely, for the other groups, the coefficients became more positive without controlling for SEN. Some of these are substantial changes, indicating that SEN is correlated with ethnicity and low performance. Considering progress through school: with SEN we estimate a coefficient of +0.372 for pupils of Black Caribbean heritage (Table 8, column 2), without we estimate 0.268; for pupils of other Black heritage the figures are 0.434 and 0.381 . For the other groups again the coefficients increase once SEN is not controlled for. So, if we do not condition on SEN status, it remains the case that pupils of all ethnic groups on average make better progress through schools than do whites. For the two groups highlighted the estimated differential progress is lower, for the other groups it is higher.

One noteworthy feature of the pattern over the secondary school cohorts is that relative to white students, all minority groups improved their relative performance most substantially for the high-stakes exams at age 16. Most of the overall 11 - 16 improvement comes about then (apart from for ethnic Chinese students). For the students, the age 14 exams matter much less than the age 16 exams. 
Table 13: Test-score vs teacher assessment

\begin{tabular}{|c|c|c|c|c|c|c|c|c|c|}
\hline \multirow{2}{*}{ Explanatory Variables } & \multicolumn{3}{|c|}{ Cohort 1 Key-stage 2} & \multicolumn{3}{|c|}{ Cohort 2 Key-stage 2} & \multicolumn{3}{|c|}{ Cohort 2 Key-stage 3} \\
\hline & English & Maths & Science & English & Maths & Science & English & Maths & Science \\
\hline \multirow{2}{*}{ Teacher Assessment } & 0.831 & 0.844 & 0.689 & 0.793 & 0.840 & 0.756 & 0.744 & 0.927 & 0.840 \\
\hline & $(944.83)^{* *}$ & $(1021.62)^{* *}$ & $(722.55)^{* *}$ & $(882.82)^{* *}$ & $(926.97)^{* *}$ & $(725.67)^{* *}$ & $(726.84)^{* *}$ & $(1224.28)^{* *}$ & $(881.47)^{* *}$ \\
\hline \multirow{2}{*}{ Black African*Teacher Assessment } & -0.042 & -0.012 & 0.005 & -0.002 & -0.030 & 0.017 & -0.015 & -0.020 & 0.015 \\
\hline & $(4.88)^{* *}$ & $(1.45)$ & $(0.55)$ & $(0.23)$ & $(3.43)^{* *}$ & $(1.76)$ & $(1.40)$ & $(2.52)^{*}$ & $(1.64)$ \\
\hline \multirow{2}{*}{ Black Caribbean*Teacher Assessment } & -0.021 & -0.031 & -0.017 & -0.032 & -0.029 & 0.008 & -0.058 & -0.015 & -0.032 \\
\hline & $(2.87)^{* *}$ & $(4.59)^{* *}$ & $(2.27)^{*}$ & $(4.34)$ & $(3.88)^{* *}$ & $(0.91)$ & $(6.44)^{* *}$ & $(2.27)^{*}$ & $(3.95)^{* *}$ \\
\hline \multirow{2}{*}{ Black Other*Teacher Assessment } & -0.041 & -0.030 & -0.042 & -0.018 & -0.028 & 0.002 & -0.018 & -0.008 & -0.006 \\
\hline & $(4.27)^{* *}$ & $(3.43)^{* *}$ & $(4.18)^{* *}$ & $(1.91)$ & $(2.85)^{* *}$ & $(0.15)$ & $(1.62)$ & $(0.96)$ & $(0.58)$ \\
\hline \multirow{2}{*}{ Bangladeshi*Teacher Assessment } & -0.041 & -0.017 & 0.014 & -0.014 & -0.027 & 0.028 & -0.077 & 0.020 & -0.005 \\
\hline & $(4.39)^{* *}$ & $(2.07)^{*}$ & $(1.50)$ & $(1.62)$ & $(2.96)^{* *}$ & $(2.91)^{* *}$ & $(7.01)^{* *}$ & $(2.46)^{*}$ & $(0.54)$ \\
\hline \multirow{2}{*}{ Indian*Teacher Assessment } & -0.051 & -0.023 & -0.002 & -0.039 & -0.026 & -0.026 & -0.054 & -0.014 & 0.007 \\
\hline & $(8.34)^{* *}$ & $(4.32)^{* *}$ & $(0.39)$ & $(7.49)^{* *}$ & $(5.09)^{* *}$ & $(4.39)^{* *}$ & $(8.68)^{* *}$ & $(3.18)^{* *}$ & $(1.21)$ \\
\hline \multirow{2}{*}{ Pakistani*Teacher Assessment } & -0.026 & -0.002 & 0.030 & -0.007 & -0.027 & 0.007 & -0.034 & -0.011 & -0.004 \\
\hline & $(4.85)^{* *}$ & $(0.39)$ & $(5.61)^{* *}$ & $(1.35)$ & $(5.10)^{* *}$ & $(1.12)$ & $(5.09)^{* *}$ & $(2.36)^{*}$ & $(0.61)$ \\
\hline \multirow{2}{*}{ Chinese*Teacher Assessment } & -0.063 & -0.011 & -0.001 & -0.016 & -0.016 & 0.028 & -0.062 & -0.004 & 0.065 \\
\hline & $(3.72)^{* *}$ & $(0.65)$ & $(0.07)$ & $(1.15)$ & $(1.07)$ & $(1.66)$ & $(3.86)^{* *}$ & $(0.30)$ & $(4.36)^{* *}$ \\
\hline \multirow{2}{*}{ Other*Teacher Assessment } & -0.021 & -0.000 & -0.014 & 0.010 & -0.007 & 0.016 & -0.013 & 0.014 & 0.022 \\
\hline & $(3.57)^{* *}$ & $(0.04)$ & $(2.21)^{*}$ & $(1.62)$ & $(1.15)$ & $(2.22)^{*}$ & $(1.72)$ & $(2.74)^{* *}$ & $(3.40)^{* *}$ \\
\hline \multirow{2}{*}{ Black African } & 1.055 & 0.218 & -0.516 & -0.372 & 0.095 & -1.117 & 0.326 & -0.199 & -1.529 \\
\hline & $(4.63)^{* *}$ & $(1.02)$ & $(2.10)^{*}$ & $(1.70)$ & $(0.43)$ & $(4.51)^{* *}$ & $(0.92)$ & $(0.78)$ & $(5.16)^{* *}$ \\
\hline \multirow{2}{*}{ Black Caribbean } & 0.340 & 0.467 & 0.151 & 0.363 & 0.114 & -0.759 & 1.373 & -0.401 & -0.226 \\
\hline & $(1.80)$ & $(2.67)^{* *}$ & $(0.74)$ & $(1.98)^{*}$ & $(0.61)$ & $(3.60)^{* *}$ & $(4.74)^{* *}$ & $(1.87)$ & $(0.90)$ \\
\hline \multirow{2}{*}{ Black Other } & 0.927 & 0.544 & 1.058 & 0.133 & 0.169 & -0.483 & 0.361 & -0.418 & -0.712 \\
\hline & $(3.69)^{* *}$ & $(2.31)^{*}$ & $(3.86)^{* *}$ & $(0.55)$ & $(0.68)$ & $(1.70)$ & $(0.97)$ & $(1.51)$ & $(2.16)^{*}$ \\
\hline \multirow{2}{*}{ Bangladeshi } & 0.885 & 0.288 & -0.916 & -0.001 & 0.176 & -1.316 & 2.139 & -1.424 & -1.600 \\
\hline & $(3.73)^{* *}$ & $(1.32)$ & $(3.67)^{* *}$ & $(0.00)$ & $(0.80)$ & $(5.51)^{* *}$ & $(6.08)^{* *}$ & $(5.43)^{* *}$ & $(5.38)^{* *}$ \\
\hline
\end{tabular}




\begin{tabular}{|c|c|c|c|c|c|c|c|c|c|}
\hline \multirow{2}{*}{ Explanatory Variables } & \multicolumn{3}{|c|}{ Cohort 1 Key-stage 2} & \multicolumn{3}{|c|}{ Cohort 2 Key-stage 2} & \multicolumn{3}{|c|}{ Cohort 2 Key-stage 3} \\
\hline & English & Maths & Science & English & Maths & Science & English & Maths & Science \\
\hline \multirow{2}{*}{ Indian } & 1.366 & 0.838 & -0.018 & 0.978 & 0.572 & 0.278 & 2.329 & 0.505 & -0.913 \\
\hline & $(8.25)^{* *}$ & $(5.51)^{* *}$ & $(0.10)$ & $(7.21)^{* *}$ & $(4.24)^{* *}$ & $(1.81)$ & $(10.96)^{* *}$ & $(3.23)^{* *}$ & $(4.94)^{* *}$ \\
\hline \multirow{2}{*}{ Pakistani } & 0.358 & -0.189 & -1.511 & -0.048 & 0.159 & -0.815 & 0.809 & -0.248 & -1.566 \\
\hline & $(2.63)^{* *}$ & $(1.48)$ & $(10.58)^{* *}$ & $(0.37)$ & $(1.23)$ & $(5.69)^{* *}$ & $(3.87)^{* *}$ & $(1.63)$ & $(8.81)^{* *}$ \\
\hline \multirow{2}{*}{ Chinese } & 2.274 & 0.867 & 0.291 & 0.671 & 0.652 & -0.857 & 2.941 & 0.336 & -2.443 \\
\hline & $(4.73)^{* *}$ & $(1.79)$ & $(0.53)$ & $(1.78)$ & $(1.57)$ & $(1.89)$ & $(5.10)^{* *}$ & $(0.69)$ & $(4.50)^{* *}$ \\
\hline \multirow{2}{*}{ Other } & 0.730 & 0.072 & 0.439 & -0.342 & 0.040 & -0.689 & 0.614 & -0.639 & -1.127 \\
\hline & $(4.54)^{* *}$ & $(0.47)$ & $(2.49)^{*}$ & $(2.10)^{*}$ & $(0.24)$ & $(3.59)^{* *}$ & $(2.47)^{*}$ & $(3.41)^{* *}$ & $(5.11)^{* *}$ \\
\hline $\mathrm{R}^{2}$ & 0.65 & 0.69 & 0.53 & 0.67 & 0.69 & 0.59 & 0.58 & 0.80 & 0.68 \\
\hline Observations & 535,237 & 535,937 & 535,826 & 438,679 & 443,354 & 436,385 & 433,501 & 441,422 & 433,931 \\
\hline
\end{tabular}

Absolute values of t-statistics in parentheses

* Significant at 5\% * $*$ Significant at $1 \%$ 


\section{Between-school factors}

One obvious factor influencing pupils' progress in attainment is the quality of schooling they receive. This in turn may depend on many factors - the quality of the teachers, the ethos and leadership of the school, and characteristics of peers. These are all difficult to measure, but one way of accounting for this in the analysis is to include school effects. We are aware that this can only provide a summary measure of the influence of school, ${ }^{23}$ and are planning future work to deal with this issue more seriously. Nevertheless, with this proviso in mind, we do this analysis for pupils at schools in London, with the results in Table 14. We focus on London only as most schools there have a diverse intake.

Comparing fixed effects and OLS means comparing average variation within a school, to variation both within and across schools. Therefore, if ethnic minority pupils attend poorer quality schools, we would expect to measure better performance for these groups (coefficients more positive or less negative) in the fixed effects then in OLS.

In all but three instances this is true, the exceptions being ethnic Bangladeshi and 'Other' minority group students in cohort 1, and ethnic Chinese students in cohort 2. Noteworthy is the halving of the coefficient for students with Black Caribbean or other Black heritage in the secondary school cohort. However, other than that most of the changes are perhaps surprisingly small, typically changing by less than $10 \%$ in the secondary school cohort. Bearing in mind the caveats attaching to this analysis above, differences in school quality appear to matter significantly for Black Caribbean or other Black heritage students, but less so for other groups.

One important factor that may influence differential ethnic attainment is the ethnic composition of class, school and neighbourhood. This is a complex problem to study as it seems very likely that a school's ethnic composition will be endogenous to its performance. We therefore postpone this issue to future work.

23 Two of the issues are as follows. First, there is no reason to suppose that the unidimensional measure of school quality provided by a fixed effect will have the same impact on progress for all ethnic groups. Second, the sorting of ethnic minority children into schools is certainly not random, and so we cannot interpret the impact of the school effect as causal rather than selection. 


\section{Table 14: School fixed effects and OLS regressions at age $11^{1}$ for cohort 1 and age $16^{2}$ cohort 2 for pupils within London LEAs}

\begin{tabular}{|c|c|c|c|c|}
\hline \multirow{2}{*}{$\begin{array}{l}\text { Explanatory } \\
\text { Variable }^{3}\end{array}$} & \multicolumn{2}{|c|}{ Cohort 1} & \multicolumn{2}{|c|}{ Cohort 2} \\
\hline & Fixed Effects & OLS & Fixed Effects & OLS \\
\hline \multirow{2}{*}{ Black African } & -0.026 & -0.065 & 0.207 & 0.205 \\
\hline & $(2.09)^{*}$ & $(5.13)^{* *}$ & $(13.57)^{* *}$ & $(12.63)^{* *}$ \\
\hline \multirow{2}{*}{ Black Caribbean } & -0.136 & -0.167 & -0.085 & -0.140 \\
\hline & $(10.69)^{* *}$ & $(13.19)^{* *}$ & $(6.02)^{* *}$ & $(9.39)^{* *}$ \\
\hline \multirow{2}{*}{ Black Other } & -0.053 & -0.065 & -0.036 & -0.060 \\
\hline & $(3.03)^{* *}$ & $(3.61)^{* *}$ & $(1.85)$ & $(2.88)^{* *}$ \\
\hline \multirow{2}{*}{ Bangladeshi } & -0.124 & -0.055 & 0.316 & 0.296 \\
\hline & $(6.03)^{* *}$ & $(3.02)^{* *}$ & $(14.04)^{* *}$ & $(14.27)^{* *}$ \\
\hline \multirow{2}{*}{ Indian } & 0.055 & 0.022 & 0.346 & 0.322 \\
\hline & $(3.86)^{* *}$ & $(1.58)$ & $(24.42)^{* *}$ & $(22.55)^{* *}$ \\
\hline \multirow{2}{*}{ Pakistani } & -0.122 & -0.193 & 0.195 & 0.169 \\
\hline & $(6.55)^{* *}$ & $(10.40)^{* *}$ & $(10.00)^{* *}$ & $(8.40)^{* *}$ \\
\hline \multirow{2}{*}{ Chinese } & 0.348 & 0.338 & 0.616 & 0.669 \\
\hline & $(9.91)^{* *}$ & $(9.17)^{* *}$ & $(18.01)^{* *}$ & $(18.00)^{* *}$ \\
\hline \multirow{2}{*}{ Other } & 0.070 & 0.080 & 0.236 & 0.233 \\
\hline & $(5.83)^{* *}$ & $(6.61)^{* *}$ & $(16.56)^{* *}$ & $(15.48)^{* *}$ \\
\hline \multirow{2}{*}{ Free School Meals } & -0.255 & -0.304 & -0.227 & -0.294 \\
\hline & $(34.17)^{* *}$ & $(39.56)^{* *}$ & $(25.41)^{* *}$ & $(30.75)^{* *}$ \\
\hline \multirow{2}{*}{ Gender } & -0.087 & -0.076 & 0.155 & 0.206 \\
\hline & $(14.68)^{* *}$ & $(12.13)^{* *}$ & $(19.33)^{* *}$ & $(28.72)^{* *}$ \\
\hline \multirow{2}{*}{$\begin{array}{l}\text { SEN without } \\
\text { statement }\end{array}$} & -1.069 & -1.044 & -0.852 & -0.869 \\
\hline & $(152.38)^{* *}$ & $(144.03)^{* *}$ & $(93.27)^{* *}$ & $(90.32)^{* *}$ \\
\hline \multirow{2}{*}{ SEN with statement } & -1.778 & -1.781 & -1.114 & -1.182 \\
\hline & $(92.16)^{* *}$ & $(87.96)^{* *}$ & $(51.63)^{* *}$ & $(50.15)^{* *}$ \\
\hline $\mathrm{R} 2$ & 0.35 & 0.36 & 0.30 & 0.31 \\
\hline Observations & 68,219 & 68,219 & 54,436 & 54,436 \\
\hline
\end{tabular}

Absolute values of t-statistics in parentheses

* Significant at $5 \% \quad * *$ Significant at $1 \%$

Notes:

1. This refers to key-stage 2 of the National Curriculum

2. This refers to key-stage 4 of the National Curriculum

3. Also included but not reported are dummies for month of birth and mosaic classification.

\section{Within-school factors}

As we discussed above, there has been much debate of practices within schools that may help or hinder the educational progress of ethnic minority students. To the extent that these practices are not universal, we would therefore expect to see important differences between schools in terms of ethnic minority pupil 
progress through school. Of course, this can be deduced indirectly from the fixed effects analysis, but here we address it directly.

Table 15: Proportion of schools/LEAs where ethnic group progress relative to Whites is positive ${ }^{1}$

\begin{tabular}{lcccc}
\hline \hline Ethnicity & $\begin{array}{c}\text { Percentage } \\
\text { schools with } \\
\text { positive } \\
\text { coefficients } \\
\text { (weighted) }\end{array}$ & $\begin{array}{c}\text { Percentage } \\
\text { schools with } \\
\text { positive } \\
\text { coefficients } \\
\text { (unweighted) }\end{array}$ & $\begin{array}{c}\text { Percentage } \\
\text { LEAs with } \\
\text { positive } \\
\text { coefficients } \\
\text { (weighted) }\end{array}$ & $\begin{array}{c}\text { Percentage } \\
\text { LEAs with } \\
\text { positive } \\
\text { coefficients } \\
\text { (unweighted) }\end{array}$ \\
\hline Black African & 0.867 & 0.816 & 0.984 & 0.816 \\
Black Caribbean & 0.528 & 0.575 & 0.490 & 0.481 \\
Black Other & 0.556 & 0.609 & 0.553 & 0.596 \\
Bangladeshi & 0.919 & 0.859 & 0.969 & 0.941 \\
Indian & 0.954 & 0.872 & 0.992 & 0.965 \\
Pakistani & 0.924 & 0.851 & 0.999 & 0.949 \\
Chinese & 0.858 & 0.846 & 0.995 & 0.965 \\
Other & 0.728 & 0.716 & 0.904 & 0.844 \\
\hline \hline
\end{tabular}

Notes:

1. This is the proportion of schools/LEAs where Key-stage 2 to 4 value added measures are greater for the specific ethnic group relative to White pupils in that school/LEA. Weighted measures take account of the ethnic group population in each school. Unweighted measures take one observation per school and ethnic group and thus do not take account of differing ethnic group populations.

In fact, the average improvement that we have shown above is close to universal for most ethnic groups. That is, for most groups, pupils improve relative to white students in almost every school. This is a striking finding. We look at (unconditional) value added between age 11 tests and age 16 tests. For each school and for each ethnic group, we ask whether that group has higher mean value added than white students. Table 15 presents the percentage of schools for which that group improves relative to whites. For the three ethnic South Asian groups, the number is over $90 \%$, for students with Black African heritage, it is $87 \%$, and $86 \%$ for ethnic Chinese students. The two groups for which this is not true are students with Black Caribbean or other Black heritage, where they improve relative to whites in about half of schools. We carry out the same exercise at LEA level, with similar results. Again for the ethnic Asian groups plus the Black African students, improvement happens essentially everywhere. These findings suggest that different school processes and practices may have an important influence on outcomes for Black Caribbean or other Black heritage students, but not for ethnic Asian students. This finding obviously ties in with 
that of the previous sub-section that inclusion of school effects appears to make a significant difference only for these groups.

\section{Conclusions}

This paper offers a detailed analysis of attainment gaps between ethnic groups in England. We exploit a universe dataset of all pupils in England, and follow two cohorts, one through primary school and one through compulsory secondary schooling. We also control for individual and neighbourhood characteristics. The results show a varied picture in terms of levels of attainment, with a number of groups out-performing white students in the highstakes terminal exams. But there are nevertheless some common patterns. After controlling for personal characteristics, all minority ethnic groups make better average progress in attainment through secondary school than do white students. These gains are substantial for some groups, only marginal for students of Black Caribbean heritage. These gains are pervasive for most of the groups, occurring in almost all schools and regions. Finally, the gains are particularly marked in the final exams that are crucial for further progress in education or jobs.

What are we to make of all this? Many of the usual explanations of attainment gaps are about levels rather than growth in attainment, and are furthermore set up to explain poorer performance by minorities. We account for poverty, and this is important in the explanation. Language may play a role - but for the groups we could consider it seems to explain only about a third of the test score gain between the ages of 11 and 16. Differences in test marking across these ages do not arise in this dataset. It may well be that the tests are not neutral between people of different cultures. But it is not obvious why this lack of neutrality should fade during secondary schooling, and fade in a similar way across students from different cultures. Turning to school quality, it is not the case that students from ethnic minorities go to higher quality schools; indeed, typically the reverse. Thus the improvement happens despite this. Differences in school practices are often thought to be important, but it seems hard to sustain this argument when students of Indian ethnicity outperform their white peers in some $90 \%$ of the schools they both attend.

This suggests more systemic factors. One such often proposed is the importance of aspirations and values inculcated by families and reinforced by communities. This involves the importance of education in general, and the role of education in getting on. Modood (2005) refers to the "Asian trajectory ... social mobility by education, self-employment and progression into the professions" (p. 302). $\mathrm{He}$ also notes the roles that communities may play in fostering such aspirations 
(p. 303). The fact that we find an important part of the relative progress comes in the most important exams lends some support to this view. If qualifications are seen as highly functional to social progress, then it makes sense to focus particular effort at that point. Whether the differential aspirations and the importance ascribed to education are an ethnic difference or a feature more generally of (relatively) recent immigrants is beyond this paper. Winder (2004) documents the "familiar immigrant paradigm": "the children of immigrants, lacking financial capital of their own, devote themselves to the acquisition of knowledge" (p. 246). He also notes that, almost by definition, they are keen to get on in life - after all, from their perspective they are emigrants. This may to some extent differentiate between the ethnic groups, with the Black African and Bangladeshi groups among the more recent arrivals.

This paper has raised a number of questions in the course of establishing some facts. We plan a number of extensions to address these. First, one factor that may be important in influencing school attainment of different ethnic groups is the ethnic composition of schools and neighbourhoods. This is a complex phenomenon to model as a school's ethnic composition is very likely to be endogenous to how well that school works for different groups. School peer group may matter directly or via influencing school processes. Neighbourhood peer groups may matter as one context for the transmission and reinforcement of values, expectations and aspirations. Second, the role of the local labour market is worth investigating. The drive to acquire qualifications may be in part a response to labour market discrimination. We might therefore expect to see differential responses to this in persistently buoyant labour markets from continually stagnant ones.

We believe that the results presented here offer a useful addition to the debate on the educational attainment of ethnic minority groups. 


\section{References}

Bali, V. and Alvarez, R. (2004). 'The Race Gap in Student Achievement Scores: Longitudinal Evidence from a Racially Diverse School District', The Policy Studies Journal, 32, 3, pp.393-415.

Bhattacharya, G., Ison, L. and Blair, M. (2003). Minority Ethnic Attainment and Participation in Education and Training: The Evidence. DfES Research Topic Paper RTP01-03, DfES, London.

Bradley, S. and Taylor, J. (2004). 'Ethnicity, Educational Attainment and the Transition from School', The Manchester School, 72, 3, pp.317-346.

Brooks-Gunn, J., Klebanov, P. and Duncan, G. (1996). 'Ethnic Differences in Children's Intelligence Test Scores: Role of Economic Deprivation, Home Environment, and Maternal Characteristics', Child Development, 67, 2, pp.396-408.

Chubb, J. and Loveless, T. (2002). Bridging the Achievement Gap. (eds) Washington D.C; The Brookings Institute.

Clotfelter, C., Ladd, H. and Vigdor, J. (2004). Teacher Quality and Minority Achievement Gaps, Terry Sanford Institute of Public Policy Working Paper Series San04-04; Duke University.

Cook, M. and Evans, W. (2000). 'Families or Schools? Explaining the Convergence in White and Black Academic Performance', Journal of Labor Economics, 18, 4, pp. 729-754.

Cook, P. and Ludwig, J. (1998). 'The Burden of "Acting White": Do Black Adolescents Disparage Academic Achievement?'. in Jencks, C. and Phillips, M. (eds.), The Black-White Test Score Gap. Washington D.C.: The Brookings Institute.

DfES (2005). Ethnicity and Education: The Evidence on Minority Ethnic Pupils. DfES Research Topic Paper RTP01-05, DfES, London.

Ehrenberg, R., Goldhaber, D., and Brewer, D. (1995). 'Do Teachers' Race, Gender, and Ethnicity Matter? Evidence from the National Educational Longitudinal Study of 1988', Industrial and Labor Relations Review, 48, 3 , pp. 547-561.

Ferguson, R. (1998a). 'Teachers' Perceptions and Expectations and the BlackWhite Test Score Gap'. in Jencks, C. and Phillips, M. (eds.), The BlackWhite Test Score Gap. Washington D.C.: The Brookings Institute.

Ferguson, R. (1998b). 'Can Schools Narrow the Black-White Test Score Gap?'. in Jencks, C. and Phillips, M. (eds.), The Black-White Test Score Gap. Washington D.C.: The Brookings Institute. 
Flanagan, A. and Grissmer, D. (2002). 'The Role of Federal Resources in Closing the Achievement Gap'. in Chubb, J. and Loveless, T. (eds.), Bridging the Achievement Gap. Washington D.C; The Brookings Institute.

Fryer, R. and Levitt, S. (2004). 'Understanding the Black-White Test Score Gap in the First Two Years of School', The Review of Economics and Statistics, 86, 2, pp. 447-464.

Fryer, R. and Levitt, S. (2005). The Black-White Test Score Gap Through Third Grade, NBER Working Paper 11049. Cambridge, MA: NBER.

Gillborn, D. and Mirza, S. (2000). Educational Inequality: Mapping Race, Class and Gender: A synthesis of research evidence, OFSTED, London.

HMSO (1974) Education disadvantage and the educational needs of immigrants: observations of the report on education of the Select Committee on Race Relations and Immigration. (Cmnd. 5720) HMSO, London.

HMSO (1985) Education for all: the Report of the committee of inquiry into the education of children from ethnic minority groups (Chairman: Lord Swann). (Cmnd. 9453) HMSO, London.

Jencks, C. and Phillips, M. (1998). The Black-White Test Score Gap. (eds) Washington D.C.: The Brookings Institute.

Klein, D. (2002). 'High Achievement in Mathematics: Lessons from Three Los Angeles Elementary Schools'. in Chubb, J. and Loveless, T. (eds.), Bridging the Achievement Gap. Washington D.C; The Brookings Institute.

Kreuger, A. and Whitmore, D. (2002). 'Would Smaller Classes Help Close the Black-White Achievement Gap?'. in Chubb, J. and Loveless, T. (eds.), Bridging the Achievement Gap. Washington D.C; The Brookings Institute.

Modood, T. (2003). 'Ethnic Differentials in Educational Performance'. in Mason, D. (ed.), Explaining Ethnic Differences: Changing Patterns of Disadvantage in Britain. Bristol; The Policy Press.

Modood, T. (2005) 'The Educational Attainments of Ethnic Minorities in Britain'. In Loury, G. C., Modood, T., and Teles, S.M. (eds.), Ethnicity, Social Mobility and Public Policy. CUP, Cambridge.

Neal, D. (2005). 'Why has Black-White Skill Convergence Stopped?' forthcoming in Handbook of Economics of Education 
Nisbett, R. (1998). 'Race, Genetics, and IQ'. in Jencks, C. and Phillips, M. (eds.), The Black-White Test Score Gap. Washington D.C.: The Brookings Institute.

Peterson, P. and Howell, W. (2002). 'Voucher Programs and the Effect of Ethnicity on Test Scores'. in Chubb, J. and Loveless, T. (eds.), Bridging the Achievement Gap. Washington D.C; The Brookings Institute.

Phillips, M. (2000). 'Understanding Ethnic Differences in Academic Achievement: Empirical Lessons from National Data', in Grissmer, D. W. and Ross, J. M. (eds.), Analytic Issues in the Assessment of Student Achievement. Washington D.C.: US. Department of Education, National Center for Education Statistics.

Phillips, M., Crouse, J. and Ralph, J. (1998). 'Does the Black-White Test Score Gap Widen After Children Enter School?', in Jencks, C. and Phillips, M. (eds.), The Black-White Test Score Gap. Washington D.C.: The Brookings Institute.

Thernstrom, A. (2002). 'The Racial Gap in Academic Achievement'. In Thernstrom, A. and Thernstrom, S. (eds.), Beyond the Color Line: New Perspectives on Race and Ethnicity in America. Hoover Institution Press Publication No. 479, Stanford.

Tikly, L. (2005). The Achievement of Minority Ethnic Learners in the UK and a Critical Analysis of Government Initiatives to Tackle Underachievement. (paper presented to Widening Participation conference)

Toenjes, L., Dworkin, G., Lorence, J. and Hill, A. (2002). 'High-Stakes Testing, Accountability, and Student Achievement in Texas and Houston'. in Chubb, J. and Loveless, T. (eds.), Bridging the Achievement Gap. Washington D.C; The Brookings Institute.

Tomlinson, S. (2001). 'Some Success, Could Do Better: Education and Race 1976-2000'. in Phillips, R. and Furlong, J. (eds.), Education, Reform and the State: Twenty-Five Years of Politics, Policy and Practice. London; Routledge.

Winder, R. (2004) Bloody Foreigners: The Story of Immigration to Britain. Abacus, London. 


\section{Appendix Tables}

Appendix Table 1: Sample sizes (Analysis cohort as \% of all observations at key-stage)

\begin{tabular}{lcccc}
\hline \hline Ethnicity & KS2 & KS3 & KS4 & KS3 \& KS4 \\
\hline Black African & 97.12 & 68.76 & 58.64 & 71.33 \\
Black Caribbean & 96.10 & 86.60 & 85.32 & 89.67 \\
Black Other & 94.96 & 87.92 & 87.03 & 91.32 \\
Bangladeshi & 95.87 & 82.56 & 81.73 & 85.29 \\
Indian & 98.93 & 90.97 & 89.59 & 91.76 \\
Pakistani & 97.04 & 87.28 & 85.60 & 89.12 \\
Chinese & 98.96 & 81.24 & 77.98 & 83.30 \\
Other & 96.51 & 81.84 & 77.87 & 84.80 \\
White & 96.02 & 92.78 & 93.43 & 95.22 \\
Total & 96.14 & 91.85 & 92.01 & 94.26 \\
\hline \hline
\end{tabular}

Size of the analysis cohort is in Table 1.

Appendix Table 2: Scores

\begin{tabular}{|c|c|c|c|c|c|c|c|}
\hline \multirow{2}{*}{ Ethnicity } & \multicolumn{2}{|c|}{$\overline{\text { KS2 }}$} & \multicolumn{2}{|c|}{ KS3 } & \multicolumn{2}{|c|}{ KS4 } & \multirow{2}{*}{$\begin{array}{c}\text { KS4 } \\
\% \text { Difference }\end{array}$} \\
\hline & Cohort & All Obs & Cohort & All Obs & Cohort & All Obs & \\
\hline Black African & $\begin{array}{l}24.151 \\
(4.42)\end{array}$ & $\begin{array}{c}24.089 \\
(4.44)\end{array}$ & $\begin{array}{l}30.787 \\
(6.60)\end{array}$ & $\begin{array}{c}29.487 \\
(6.96)\end{array}$ & $\begin{array}{l}40.088 \\
(17.65)\end{array}$ & $\begin{array}{l}36.220 \\
(18.32)\end{array}$ & 10.68 \\
\hline $\begin{array}{l}\text { Black } \\
\text { Caribbean }\end{array}$ & $\begin{array}{l}24.247 \\
(4.06)\end{array}$ & $\begin{array}{c}24.178 \\
(4.07)\end{array}$ & $\begin{array}{l}29.895 \\
(5.93)\end{array}$ & $\begin{array}{c}29.487 \\
(6.08)\end{array}$ & $\begin{array}{l}33.567 \\
(16.88)\end{array}$ & $\begin{array}{l}32.491 \\
(17.12)\end{array}$ & 3.31 \\
\hline Black Other & $\begin{array}{l}24.637 \\
(4.10)\end{array}$ & $\begin{array}{l}24.531 \\
(4.12)\end{array}$ & $\begin{array}{l}30.778 \\
(6.22)\end{array}$ & $\begin{array}{c}30.500 \\
(6.33)\end{array}$ & $\begin{array}{l}35.488 \\
(18.27)\end{array}$ & $\begin{array}{l}35.065 \\
(18.37)\end{array}$ & 1.21 \\
\hline Bangladeshi & $\begin{array}{l}23.700 \\
(4.38)\end{array}$ & $\begin{array}{l}23.634 \\
(4.39)\end{array}$ & $\begin{array}{l}29.961 \\
(6.35)\end{array}$ & $\begin{array}{l}29.495 \\
(6.49)\end{array}$ & $\begin{array}{l}40.130 \\
(17.98)\end{array}$ & $\begin{array}{l}38.749 \\
(18.38)\end{array}$ & 3.56 \\
\hline Indian & $\begin{array}{l}25.412 \\
(4.06)\end{array}$ & $\begin{array}{l}25.387 \\
(4.07)\end{array}$ & $\begin{array}{l}33.635 \\
(6.39)\end{array}$ & $\begin{array}{c}33.491 \\
(6.58)\end{array}$ & $\begin{array}{l}47.230 \\
(17.35)\end{array}$ & $\begin{array}{l}46.699 \\
(17.77)\end{array}$ & 1.14 \\
\hline Pakistani & $\begin{array}{l}23.241 \\
(4.30)\end{array}$ & $\begin{array}{l}23.183 \\
(4.31)\end{array}$ & $\begin{array}{l}29.573 \\
(6.37)\end{array}$ & $\begin{array}{c}29.276 \\
(6.47)\end{array}$ & $\begin{array}{l}37.428 \\
(17.99)\end{array}$ & $\begin{array}{l}36.683 \\
(18.21)\end{array}$ & 2.03 \\
\hline Chinese & $\begin{array}{l}26.923 \\
(4.07)\end{array}$ & $\begin{array}{c}26.909 \\
(4.08)\end{array}$ & $\begin{array}{l}36.416 \\
(6.49)\end{array}$ & $\begin{array}{c}36.145 \\
(6.76)\end{array}$ & $\begin{array}{l}53.713 \\
(17.68)\end{array}$ & $\begin{array}{l}51.940 \\
(19.61)\end{array}$ & 3.41 \\
\hline Other & $\begin{array}{l}25.605 \\
(4.33)\end{array}$ & $\begin{array}{c}25.506 \\
(4.37)\end{array}$ & $\begin{array}{c}33.174 \\
(6.81)\end{array}$ & $\begin{array}{c}32.435 \\
(7.21)\end{array}$ & $\begin{array}{l}42.821 \\
(19.63)\end{array}$ & $\begin{array}{l}41.035 \\
(20.30)\end{array}$ & 4.35 \\
\hline White & $\begin{array}{l}26.077 \\
(4.09) \\
\end{array}$ & $\begin{array}{c}25.952 \\
(4.15) \\
\end{array}$ & $\begin{array}{r}33.567 \\
(6.40) \\
\end{array}$ & $\begin{array}{l}33.35 \\
(6.52) \\
\end{array}$ & $\begin{array}{l}41.576 \\
(18.88) \\
\end{array}$ & $\begin{array}{c}41.18 \\
(19.08) \\
\end{array}$ & 0.96 \\
\hline
\end{tabular}

Standard deviations in parentheses 


\section{Appendix Table 3: Gain and Acceleration}

\begin{tabular}{|c|c|c|c|c|c|c|}
\hline \multirow[t]{2}{*}{ Ethnicity } & \multicolumn{2}{|c|}{$\begin{array}{c}\text { Gain } \\
\text { (KS3-KS2) }\end{array}$} & \multicolumn{2}{|c|}{$\begin{array}{c}\text { Gain } \\
\text { (KS4-KS3) }\end{array}$} & \multicolumn{2}{|c|}{$\begin{array}{c}\text { Acceleration } \\
\text { (KS4-KS3) - (KS3- } \\
\text { KS2) }\end{array}$} \\
\hline & Cohort & All Obs & Cohort & All Obs & Cohort & All Obs \\
\hline Black African & 0.029 & -0.137 & 0.325 & 0.295 & 0.296 & 0.432 \\
\hline Black Caribbean & -0.133 & -0.159 & 0.118 & 0.099 & 0.251 & 0.258 \\
\hline Black Other & -0.091 & -0.089 & 0.084 & 0.080 & 0.175 & 0.169 \\
\hline Bangladeshi & 0.009 & -0.028 & 0.455 & 0.426 & 0.446 & 0.454 \\
\hline Indian & 0.165 & 0.159 & 0.262 & 0.237 & 0.097 & 0.078 \\
\hline Pakistani & 0.06 & 0.047 & 0.373 & 0.351 & 0.313 & 0.304 \\
\hline Chinese & 0.232 & 0.199 & 0.173 & 0.110 & -0.059 & -0.089 \\
\hline Other & 0.696 & -0.029 & 0.100 & 0.101 & -0.596 & 0.130 \\
\hline White & -0.006 & 0.003 & -0.035 & -0.030 & -0.029 & -0.033 \\
\hline
\end{tabular}

This takes the z-score representation of the Key Stage scores, and computes the difference in the group means between stages using both the data from our analysis cohort and using all available data at each individual Key Stage. The final pair of columns calculates the change in the gain. 